\title{
Robust BOLD Responses to Faces But Not to Conditioned Threat: Challenging the Amygdala's Reputation in Human Fear and Extinction Learning
}

\author{
${ }^{\circledR}$ Renée M. Visser, ${ }^{1 *}$ Joe Bathelt, ${ }^{2 *}{ }^{\circledR}$ H. Steven Scholte, ${ }^{1}$ and Merel Kindt ${ }^{1}$ \\ ${ }^{1}$ Department of Psychology, University of Amsterdam, 1018 WT, Amsterdam, The Netherlands, and ${ }^{2}$ Department of Psychology, Royal Holloway \\ University of London, Egham TW20 0EX, United Kingdom
}

Most of our knowledge about human emotional memory comes from animal research. Based on this work, the amygdala is often labeled the brain's "fear center", but it is unclear to what degree neural circuitries underlying fear and extinction learning are conserved across species. Neuroimaging studies in humans yield conflicting findings, with many studies failing to show amygdala activation in response to learned threat. Such null findings are often treated as resulting from MRI-specific problems related to measuring deep brain structures. Here we test this assumption in a mega-analysis of three studies on fear acquisition ( $n=98$; 68 female) and extinction learning $(n=79 ; 53$ female). The conditioning procedure involved the presentation of two pictures of faces and two pictures of houses: one of each pair was followed by an electric shock [a conditioned stimulus $\left(\mathrm{CS}^{+}\right)$], the other one was never followed by a shock $\left(\mathrm{CS}^{-}\right)$, and participants were instructed to learn these contingencies. Results revealed widespread responses to the $\mathrm{CS}^{+}$compared with the $\mathrm{CS}^{-}$in the fear network, including anterior insula, midcingulate cortex, thalamus, and bed nucleus of the stria terminalis, but not the amygdala, which actually responded stronger to the $\mathrm{CS}^{-}$. Results were independent of spatial smoothing, and of individual differences in trait anxiety and conditioned pupil responses. In contrast, robust amygdala activation distinguished faces from houses, refuting the idea that a poor signal could account for the absence of effects. Moving forward, we suggest that, apart from imaging larger samples at higher resolution, alternative statistical approaches may be used to identify cross-species similarities in fear and extinction learning.

Key words: amygdala; emotional memory; extinction learning; functional magnetic resonance imaging; Pavlovian fear conditioning; translational science

Significance Statement

The science of emotional memory provides the foundation of numerous theories on psychopathology, including stress and anxiety disorders. This field relies heavily on animal research, which suggests a central role of the amygdala in fear learning and memory. However, this finding is not strongly corroborated by neuroimaging evidence in humans, and null findings are too easily explained away by methodological limitations inherent to imaging deep brain structures. In a large nonclinical sample, we find widespread BOLD activation in response to learned fear, but not in the amygdala. A poor signal could not account for the absence of effects. While these findings do not disprove the involvement of the amygdala in human fear learning, they challenge its typical portrayals and illustrate the complexities of translational science.

Received Apr. 21, 2021; revised 0ct. 11, 2021; accepted 0ct. 14, 2021.

Author contributions: R.M.V., H.S.S., and M.K. designed research; R.M.V. performed research; R.M.V. and J.B. analyzed data; R.M.V. and J.B. wrote the paper.

R.M.V. receives support from the Netherlands Organization for Scientific Research (NWO Veni Grant 016.195.246). J.B. was supported by an Amsterdam Brain and Cognition talent grant. M.K. received support through ERC (European Research Council) Advanced Grant 743263.

The authors declare no competing financial interests.

*R.M.V. and J.B. contributed equally to this work.

Correspondence should be addressed to Renée M. Visser at r.m.visser@uva.nl.

https://doi.org/10.1523/JNEUROSCI.0857-21.2021

Copyright $\odot 2021$ Visser, Bathelt et al.

This is an open-access article distributed under the terms of the Creative Commons Attribution 4.0 International license, which permits unrestricted use, distribution and reproduction in any medium provided that the original work is properly attributed.

\section{Introduction}

The science of emotional memory provides the foundation of numerous theories on psychopathology, spanning studies in rodents and studies in patients with stress and anxiety disorders. The success of translating mechanistic insights from nonhuman animals to human dysfunction/function depends on careful translation between levels of increasing complexity (and back), and critically evaluating the appropriateness of such translation. The typical paradigm to study fear learning and memory is Pavlovian conditioning. In this model, a neutral stimulus [i.e., a conditioned stimulus $\left(\mathrm{CS}^{+}\right)$; e.g., a geometric shape] is paired with an aversive outcome [unconditioned stimulus (US); e.g., 
Table 1. Overview of participant characteristics per study

\begin{tabular}{|c|c|c|c|c|c|c|c|c|c|c|c|c|}
\hline & \multirow[b]{2}{*}{$n$} & \multirow[b]{2}{*}{$\operatorname{Sex}(M / F)$} & \multicolumn{2}{|l|}{ Age (years) } & \multicolumn{2}{|l|}{ STAI-T } & \multicolumn{2}{|l|}{ ASI } & \multicolumn{2}{|c|}{ US intensity (mA) } & \multicolumn{2}{|c|}{ US unpleasantness } \\
\hline & & & Mean (SD) & Range & Mean (SD) & Range & Mean (SD) & Range & Mean (SD) & Range & Mean (SD) & Range \\
\hline Study 1 & 19 & $4 / 15$ & $22.1(3.3)$ & $18-31$ & 36.5 (11.4) & $22-59$ & $10.3(5.6)$ & $3-29$ & $19.6(5.0)$ & $11-32$ & NA & NA \\
\hline Study 3 & 41 & $11 / 30$ & $20.6(1.8)$ & $18-24$ & $34.7(8.8)$ & $22-53$ & $10.6(5.2)$ & $2-23$ & $26.5(13.3)$ & $8-60$ & $3.6(1.5)$ & $1.5-8$ \\
\hline Total & 98 & $30 / 68$ & $22.1(3.3)$ & $18-33$ & $35.2(9.2)$ & $20-59$ & 10.1 (5.4) & $2-29$ & $28.3(14.2)$ & $8-71$ & $3.5(1.4)$ & $1.5-8$ \\
\hline
\end{tabular}

Study 1 is Visser et al (2011), Study 2 is Visser et al. (2013), and Study 3 is Visser et al. (2015). US unpleasantness was measured on a scale from 1 (extremely unpleasant) to 9 (not unpleasant). NA, Not available; M, male; F, female; ASI, Anxiety Status Inventory.

electric shock], by which the neutral stimulus acquires an aversive association and elicits a fear response. The appeal of this model is its robustness (effects are replicable), and the availability of behavioral, physiological, and psychological readouts of the learning process, making it ideal for research across species (Fanselow and Pennington, 2018; Haaker et al., 2019).

Based on work in nonhuman animals the amygdala has obtained the reputation of being a hub in the brain's fear circuitry, in the media regularly referred to as the brain's "fear center" (critically discussed by LeDoux, 2020). Although it is unknown whether defensive responses in animals entail a subjective experience of fear (LeDoux, 2014), mechanistic work in rodents and nonhuman primates directly informs theories on human fear learning (Haaker et al., 2019). Decades of work in animals have shown that the amygdala has a critical role in the acquisition, storage, and/or expression of CS-US associations, as well as in creating fear-inhibiting memory traces as a result of extinction learning (LeDoux, 2000; Davis et al., 2008; Tovote et al., 2015). It also highlights that the amygdala is not a singular, indivisible natural kind, but a collection of structurally and functionally diverse subnuclei (Swanson and Petrovich, 1998).

It is, however, not self-evident that the neural circuitry underlying emotional learning and memory is conserved across species. While selective damage to the amygdalar complex in humans is associated with weaker fear conditioning (Bechara et al., 1995; Klumpers et al., 2015), functional magnetic resonance imaging (fMRI) studies have yielded conflicting findings. Whereas some report amygdala responses to learned threat $\left(\mathrm{CS}^{+}>\mathrm{CS}^{-}\right.$; Büchel et al., 1998; LaBar et al., 1998; Reddan et al., 2018; Sjouwerman et al., 2020), recent influential meta-analyses on threat conditioning (Fullana et al., 2016) and extinction (Fullana et al., 2018) did not reveal amygdala activation at all. Explanations for conflicting findings can be summarized as follows: (1) insufficiently fear-provoking conditioning procedures; (2) heterogeneity of experimental designs and analytical methods; and (3) the functional heterogeneity of the amygdala (subtle effects) combined with small study samples leading to a lack of statistical power (Sehlmeyer et al., 2009; Mechias et al., 2010; Fullana et al., 2016, 2018, 2020; Sevenster et al., 2018; Shackman and Fox, 2021).

Here we focus on a key alternative interpretation. The amygdala is located deep within the temporal lobe near cavities, causing dropout of BOLD signal (Weiskopf et al., 2006; Olman et al., 2009). Therefore, one of the prevailing post hoc explanations for null findings is failure to measure a proper signal in this area (Sehlmeyer et al., 2009; Fullana et al., 2020). This implies that with a proper signal, amygdala responses to learned threat should be observed. Here, we test this assumption by directly assessing susceptibility artifacts, and by capitalizing on the known responsiveness of the amygdala to faces (Rutishauser et al., 2015), in a mega-analysis of three independent fear-conditioning studies (Visser et al., 2011, 2013, 2015; total, $n=98$ ). The experimental paradigm involved the repeated presentation of two pictures of neutral faces and two pictures of houses. During acquisition, one of each pair was followed by an electric shock $\left(\mathrm{CS}^{+} ; 46 \%\right.$ reinforcement), while the other one was never reinforced $\left(\mathrm{CS}^{-}\right)$. During extinction learning, none of the stimuli were reinforced. This large dataset offers the unique opportunity to examine amygdala activation to learned threat $\left(\mathrm{CS}^{+}\right.$vs $\left.\mathrm{CS}^{-}\right)$ and to test, using the exact same data (contrasting faces with houses), whether a poor signal could account for an absence of effects. We also explored the role of the bed nucleus of the stria terminalis (BNST), a key subdivision of the central extended amygdala that has been implicated in fear and anxiety.

\section{Materials and Methods}

\section{Participants}

In the current study, a total of 98 complete fear acquisition datasets from healthy volunteers ( 68 female, 30 male) between 18 and 33 years of age are included (Table 1), with a subsample of 79 participants (53 female, 26 male) also having data on extinction learning. This already excludes some participants (study $1, n=3$; study 2, $n=16$; study $3, n=11$ ) based on criteria that have been detailed previously (Visser et al., 2011, 2013, 2015), such as excessive head motion, sleepiness, equipment failure, and unawareness of stimulus-outcome contingencies. Participants earned partial course credit or financial reimbursement for their participation. All participants gave their written informed consent before participation, were screened to have normal or corrected-to-normal vision, and were naive to the purpose of the experiment. Procedures were executed in compliance with relevant laws and institutional guidelines and were approved by the University of Amsterdam's ethics committee (2010-CP1246, 2011-CP-1565, and 2013-CP-2387).

\section{Experimental design}

The conditioning procedure was similar across studies and took place during fMRI scanning. It involved the presentation of two $\mathrm{CS}^{+}$, a picture of a face (neutral expression) and a picture of a house, which were followed by electric stimulation (US) delivered to the shin, on 6 of 13 trials (46\% reinforcement). The electrical stimulation was delivered twice for $2 \mathrm{~ms}$, with a delay of $300 \mathrm{~ms}$ (the second coterminating with the CS), by a current stimulator (model DS7A, Digitimer) through MRI-compatible carbon electrodes attached to the right shinbone. The US intensity was determined by adapting the level individually to be clearly aversive (i.e., participants were encouraged to select the maximum tolerable intensity). Two other stimuli (CSs), also a picture of a face (neutral expression) and a picture of a house, were never followed by electric stimuli. Study 2 had an additional stimulus pair that was followed by neutral sounds; responses to these stimuli are not analyzed here. CSs were presented for $6 \mathrm{~s}$ with an interval of $22 \mathrm{~s}$ (study 1 ), or $4 \mathrm{~s}$ with an interstimulus interval of $20 \mathrm{~s}$ (studies 2 and 3). Each trial onset was triggered by the start of the acquisition of a BOLD-MRI volume. The order of stimulus presentation was fixed (counterbalanced across participants) and consisted of a repeating sequence of four target trials, with filler trials of the same stimuli in between. This target and filler structure was used (1) to control for temporal proximity when comparing trial-to-trial pattern similarity across conditions (although not relevant for the present study, it is necessary to control for this when using similarity analyses; Mumford et al., 
2014; Visser et al., 2016); (2) to ensure that shock-related activity could not confound CS-related activity (Büchel et al., 1998); and (3) to make the trial order appear random to the participant. In total, the conditioning phase consisted of 52 trials: 28 target trials ( 7 per stimulus type) and 24 filler trials (6 per stimulus type), including all reinforced $\mathrm{CS}^{+}$trials (i.e., trials that coterminated with a shock). The first two sequences of target trials (eight trials in total, two per stimulus type) were uninterrupted by (reinforced) filler trials, acting as a baseline/habituation phase.

Two studies had an extinction learning session, either $48 \mathrm{~h}$ (study 3 ) or several weeks (study 2) after fear acquisition. The extinction phase is particularly relevant for translational research given that many of the hypotheses coming from work in nonhuman animals are about (changing) the long-term storage and expression of consolidated fear memories, with implications for persistent fears and treatment for patients. During this session, the shock intensity was explicitly set at the individual level, as determined in the previous session, but none of the CS stimuli were reinforced. The extinction phase also consisted of 52 trials: 28 target trials (7 per stimulus type) and 24 filler trials (6 per stimulus type). For each phase, we constrained our analyses to target trials. The rationale for using this design with target and filler trials has been comprehensively described and tested (Visser et al., 2016).

Participants were told that two of the stimuli might be followed by the electric stimulation, whereas the other stimuli would never be followed by the electric stimulation. They were instructed to learn and remember the specific contingencies. Note that while this is different from "instructed fear learning" (Phelps et al., 2001; Mechias et al., 2010; Klumpers et al., 2017; exp. 2) where participants are told beforehand which stimulus is or is not followed by a shock, our instructions do reduce uncertainty related to the safe stimuli $\left(\mathrm{CS}^{-}\right)$once contingencies have been learned. This presumably leads to enhanced differential fear responding, compared with paradigms where no instructions are given (Reddan et al., 2018; Sjouwerman et al., 2020), and to fewer unaware participants, though in both protocols direct experience of the shock is central to learning the contingencies. Before and after scanning, participants filled out questionnaires to measure trait and state anxiety (Spielberger et al., 1983) and anxiety sensitivity (Peterson and Reiss, 1992). Apart from BOLD activity, studies 2 and 3 included additional measures of conditioned fear, such as retrospective US expectancies ["How much did you expect a shock when this picture was presented?" from 1 ("certainly not") to 9 ("certainly")], US unpleasantness ratings ["How unpleasant was the shock?" from 1 ("extremely unpleasant") to 9 ("not unpleasant")] and pupil dilation to the CS (see section Conditioned pupil response). Study 3 was originally set up as a betweensubject design, testing the effects of the administration of $20 \mathrm{mg}$ of yohimbine $\mathrm{HCl}$ versus placebo on fear acquisition. Given that none of the outcome measures showed any group differences (Visser et al., 2015), we report summary statistics for the entire study sample rather than per group. Notably, similar results were obtained when adding pharmacological manipulation as a fixed factor in the models used to examine voxel-wise amygdala responses to learned threat. Parametric maps for this control analysis are available on OSF (https://osf.io/cq5zr/).

\section{Conditioned pupil response}

In studies 2 and $3(n=79)$, pupil dilation responses were collected as an independent measure of anticipatory autonomic arousal (Finke et al., 2021). Pupil size was recorded continuously throughout MRI scanning, using a remote nonferromagnetic infrared long range mount eye tracker (model EyeLink 1000, SR Research). Before task onset, a 9-point calibration procedure was performed. Participants were instructed not to move their eyes and fixate on the center of the screen for as long as a stimulus was presented. Before stimulus onset, a white fixation cross turned pink for $1 \mathrm{~s}$ to enable the participant to focus in time.

Eye-tracking data were processed and analyzed in MATLAB (version 2015a; MathWorks). Data were sampled at/downsampled to 500 or $250 \mathrm{~Hz}$. Samples around series of missing samples were regarded as unreliable and were removed ( $100 \mathrm{~ms}$ before and $100 \mathrm{~ms}$ after each series of 10 missing samples) and replaced by a linear trend at point, using the entire time series. Trials that experienced substantial signal loss, affecting $>50 \%$ of the samples of the prestimulus baseline and/or the $4 \mathrm{~s}$ after
Table 2. Overview of scan parameters

\begin{tabular}{llll}
\hline Parameter & Study 1 & Study 2 & Study 3 \\
\hline BOLD fMRI & & & \\
Slice orientation & Sagittal & Sagittal & Axial \\
TR & $2000 \mathrm{~ms}$ & $2000 \mathrm{~ms}$ & $2000 \mathrm{~ms}$ \\
TE & $27.63 \mathrm{~ms}$ & $27.63 \mathrm{~ms}$ & $27.63 \mathrm{~ms}$ \\
Flip angle & $90^{\circ}$ & $76.1^{\circ}$ & $76.1^{\circ}$ \\
Voxel size & $2.4 \times 2.4 \times 3.1 \mathrm{~mm}$ & $3 \times 3 \times 3.3 \mathrm{~mm}$ & $3 \times 3 \times 3.3 \mathrm{~mm}$ \\
Anatomical T1 & & & \\
TR & $8.141 \mathrm{~ms}$ & $8.124 \mathrm{~ms}$ & $8.11 \mathrm{~ms}$ \\
TE & $3.74 \mathrm{~ms}$ & $3.72 \mathrm{~ms}$ & $3.73 \mathrm{~ms}$ \\
Flip angle & $8^{\circ}$ & $8^{\circ}$ & $8^{\circ}$ \\
\hline
\end{tabular}

Study 1 is Visser et al. (2011), Study 2 is Visser et al. (2013), Study 3 is Visser et al. (2015). TR, Repetition time; $\mathrm{TE}_{\text {, echo time. }}$

stimulus onset, were treated as a "missing trial" and replaced entirely by estimating the linear trend at point over trials for each condition separately (Visser et al., 2013, 2015, 2016; Leuchs et al., 2019). Participants who ended up having a third or more missing trials per phase were excluded ( $n=3$ for acquisition; $n=2$ for extinction learning). Next, the interpolated pupil time series was low-pass filtered (third-order Butterworth filter, $4 \mathrm{~Hz}$ ). The baseline pupil diameter was the average value during the $500 \mathrm{~ms}$ before each CS onset. The pupil response to the CS was calculated as the peak change from baseline in a window from 0 to $4 \mathrm{~s}$ after picture onset. Next, data were $z$-transformed across all trials within an individual (separately for acquisition and extinction) to reduce between-subject variability.

\section{fMRI data and image acquisition}

All scans were acquired on a 3 T MRI scanner (Achieva TX, Philips). Study 1 used an 8-channel head coil, studies 2 and 3 used a 32-channel head coil. All scans were acquired using gradient echo, echoplanar pulse sequences and covered the whole brain. High-resolution anatomical images were acquired as part of all studies and were used for image registration in the current study (Table 2, sequence details). Foam pads were used in all studies to minimize head motion.

\section{fMRI data preprocessing}

All images were converted from native PAR/REC to NIfTI- 1 format using the dicm2nii toolbox (https://github.com/xiangruili/dicm2nii). The T1-weighted (T1w) image was corrected for intensity nonuniformity using N4BiasFieldCorrection [antsApplyTransforms (ANTs) 2.3.3] and was used as T1w reference throughout the workflow. The T1w reference was then skull stripped with a Nipype implementation of the antsBrainExtraction.sh workflow (ANTs 2.3.3), using OASIS30ANTs as the target template. Brain tissue segmentation of CSF, white matter (WM) and gray matter (GM) was performed on the brain-extracted T1w using FAST (Zhang et al., 2001; FSL 5.0.9; RRID:SCR_002823). Brain surfaces were reconstructed using recon-all (Dale et al., 1999; FreeSurfer 6.0.1; RRID:SCR_001847), and the brain mask estimated previously was refined with a custom variation of the method to reconcile ANTsderived and FreeSurfer-derived segmentations of the cortical GM of Mindboggle (RRID:SCR_002438; Klein et al., 2017). Volume-based spatial normalization to the FSL MNI ICBM 152 nonlinear sixth Generation Asymmetric Average Brain Stereotaxic Registration Model standard space (TemplateFlow ID: MNI152NLin6Asym; RRID:SCR_ 002823; Evans et al., 2012) was performed through nonlinear registration with antsRegistration (Avants et al., 2008; ANTs 2.2.0; RRID:SCR 004757) using brain-extracted versions of both T1w volume and template.

For each BOLD run per subject (across all sessions), the following preprocessing was performed. First, a reference volume and its skullstripped version were generated using a custom methodology of fMRIPrep. Head-motion parameters with respect to the BOLD reference (transformation matrices, and six corresponding rotation and translation parameters) are estimated before any spatiotemporal filtering using mcflirt (FSL, version 5.0.9; Jenkinson et al., 2002). Susceptibility distortion 
correction (SDC) was omitted. The BOLD time series (slice-timing correction was not applied) were resampled onto their original, native space by applying the transforms to correct for head motion. These resampled BOLD time series will be referred to as "preprocessed BOLD in original space" or just "preprocessed BOLD." The BOLD reference was then coregistered to the T1w reference using bbregister (FreeSurfer), which implements boundary-based registration (Greve and Fischl, 2009). Coregistration was configured with 6 degrees of freedom. Several confounding time series were calculated based on the preprocessed BOLD, as follows: framewise displacement (FD), spatial standard deviation of successive difference images (DVARS), and three region-wise global signals. FD was computed using two formulations following the studies by Power et al. (2014; absolute sum of relative motions) and Jenkinson et al. (2002; relative root mean square displacement between affines). FD and DVARS are calculated for each functional run, both using their implementations in Nipype (following the definitions by Power et al., 2014). The three global signals are extracted within the CSF, the WM, and the whole-brain masks.

The BOLD time series were resampled into several standard spaces, correspondingly generating the following spatially normalized, preprocessed BOLD runs: MNI152NLin6Asym and MNI152NLin2009cAsym. First, a reference volume and its skull-stripped version were generated using a custom methodology of fMRIPrep. All resamplings can be performed with a single interpolation step by composing all the pertinent transformations (i.e., head motion transform matrices, SDC when available, and coregistrations to anatomical and output spaces). Gridded (volumetric) resamplings were performed using ANTs, configured with Lanczos interpolation to minimize the smoothing effects of other kernels (Lanczos, 1964). Nongridded (surface) resamplings were performed using mri_vol2surf (FreeSurfer). The statistical analyses were performed in the FSL MNI152NLin6Asym space at $2 \mathrm{~mm}$ isotropic resolution.

Many internal operations of fMRIPrep use Nilearn 0.6.2 (Abraham et al., 2014; RRID:SCR_001362), mostly within the functional processing workflow. For more details of the pipeline, see the section corresponding to workflows in fMRIPrep's documentation (https://fmriprep.org/en/ stable/workflows.html).

The statistical analysis presented here included the canonical six motion parameters (i.e., rotation and translation in three directions), and their first temporal derivative as nuisance regressors (Siegel et al., 2014). Importantly, as the degree of spatial smoothing may have an impact on the results, we compared the results using full-width at half-maximum Gaussian smoothing kernels with a diameter of 2, 5, or $8 \mathrm{~mm}$, with the latter two sizes being the most common in fMRI studies on conditioning.

All of the raw imaging data in BIDS format (Gorgolewski et al., 2016) and analysis scripts have been made publicly available in the following online repositories: raw data Study 1, 10.18112/openneuro. ds003553.v1.0.0; raw data Study 2, 10.18 112/openneuro.ds003550. v1.0.1; raw data Study 3, 10.18112/openneuro.ds003554.v1.0.0; and derivatives and code for all three studies, https://osf.io/cq5zr/.

\section{Statistical analysis}

Conditioned pupil response

The $z$-transformed pupil dilation responses were averaged over face and house stimuli. This was because we were not interested in the difference between faces and houses, as this analysis only served as an independent check for whether the fear-conditioning procedure was successful and to identify "learners" (see section Relation between amygdala and indices of fear). Statistical comparisons of the learned associations were performed by within-subject ANOVA, using SPSS (version 26; IBM). Differential aversive learning and extinction learning were assessed by a main effect of stimulus type $\left(\mathrm{CS}^{+}\right.$vs $\mathrm{CS}^{-}$, averaged over faces and houses) and the interaction of trial $(13) \times$ stimulus type $\left(\mathrm{CS}^{+}\right.$vs $\left.\mathrm{CS}^{-}\right)$, tested separately for the acquisition and extinction phase.

\section{ROI analysis}

Anatomical mask definition. Amygdala masks were obtained from the probabilistic Harvard-Oxford subcortical atlas, created using different probability thresholds $(p>0.01, p>0.25$, and $p>0.50$ ) and binarized. The more conservative thresholds of $p>0.25$ and $p>0.50$ allow

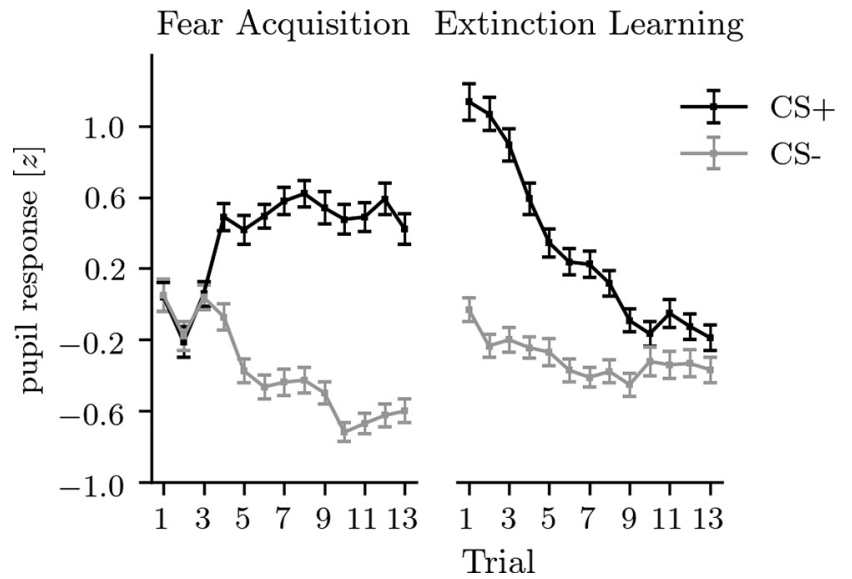

Figure 1. The z-transformed pupil dilation responses (peak minus baseline) for the fear acquisition phase $(n=76)$ and the extinction learning phase $(n=77)$ show strong acquisition and extinction of fear. Error bars represent 1 SEM.

for inferences with higher anatomical specificity, while results at a liberal threshold are reported to minimize the chance of missing small clusters of activation in the periamygdaloid cortex (see Fig. 2). Furthermore, we explored activation in the BNST, a small region surrounding the internal capsule. While often overlooked, accumulating evidence suggests that this region is consistently involved in conditioned responses to the $\mathrm{CS}^{+}$ (Fullana et al., 2016; Klumpers et al., 2017), and to threat anticipation more broadly (Hur et al., 2020), even forming a functional unit with a dorsal region of the central amygdala, together referred to as the "central extended amygdala" (Davis et al., 2010; Shackman and Fox, 2016; Torrisi et al., 2018; Fox and Shackman, 2019; Hur et al., 2020). Research in rodents and nonhuman primates suggests that the extended amygdala has a critical role in threat anticipation, both when the threat is unexpected (e.g., in paradigms modeling general anxiety) and when it is expected (e.g., in Pavlovian fear conditioning; Shackman and Fox, 2016; Fox and Shackman, 2019). Several anatomical BNST masks are available via open source platforms. We used one from Torrisi et al. (2018; https://afni.nimh. nih.gov/afni/community/board/read.php?1,149436,149436).

Voxel-wise ROI analysis. We investigated the voxel-wise BOLD responses within bilateral amygdala regions of interest (ROIs) to ensure detection of smaller effects that would not survive multiple-comparison correction across the whole brain. After preprocessing (including 2, 5, or 8 $\mathrm{mm}$ smoothing), imaging data were further analyzed using FSL FEAT version 6.0 software. Four regressors of interest $\left(\mathrm{CS}^{+}\right.$face, $\mathrm{CS}^{-}$face, $\mathrm{CS}^{+}$ house, $\mathrm{CS}^{-}$house) were included in a voxel-wise ROI analysis using a general linear model (GLM), with each of the regressors including seven (target) trials (see subsection Experimental design). Stimulus onsets were modeled using a double gamma hemodynamic response function and a duration of $6 \mathrm{~s}$ (study 1) or $4 \mathrm{~s}$ (study 2 and 3). Regressors of no interest included filler trials, the USs, temporal derivatives for each regressor, and six motion parameters and their temporal derivatives. Normalized parameter estimates in each contrast of interest (cope) based on firstlevel analysis were combined across individuals to obtain group-level statistical maps. To this end, we performed a permutation-based analysis with 5000 permutations and threshold-free cluster enhancement (TFCE, Winkler et al., 2014) as implemented in FSL randomize. This voxel-wise analysis was conducted separately for the left and right amygdala masks to maximize the chance of detecting even small clusters of activation.

Susceptibility artifacts. We examined potential signal dropout because of field inhomogeneities in anatomically defined amygdala masks (at a liberal threshold of $p>0.01$ ) for each individual. Susceptibility artifacts were defined as a drop-off in signal intensity to $<50 \%$ of the mean EPI signal (acquisition and extinction phase analyzed separately) for that participant (Olman et al., 2009). Dropout was low in the left (mean $=1.7 \%, \mathrm{SD}=2.1$ ) and right $($ mean $=1.2 \%, \mathrm{SD}=1.7$ ) amygdala (range, $0-11.7 \%)$. Signal dropout across participants is depicted for the fear acquisition and extinction phase separately (see Fig. 2). 
Fear Acquisition $(\mathrm{n}=98)$
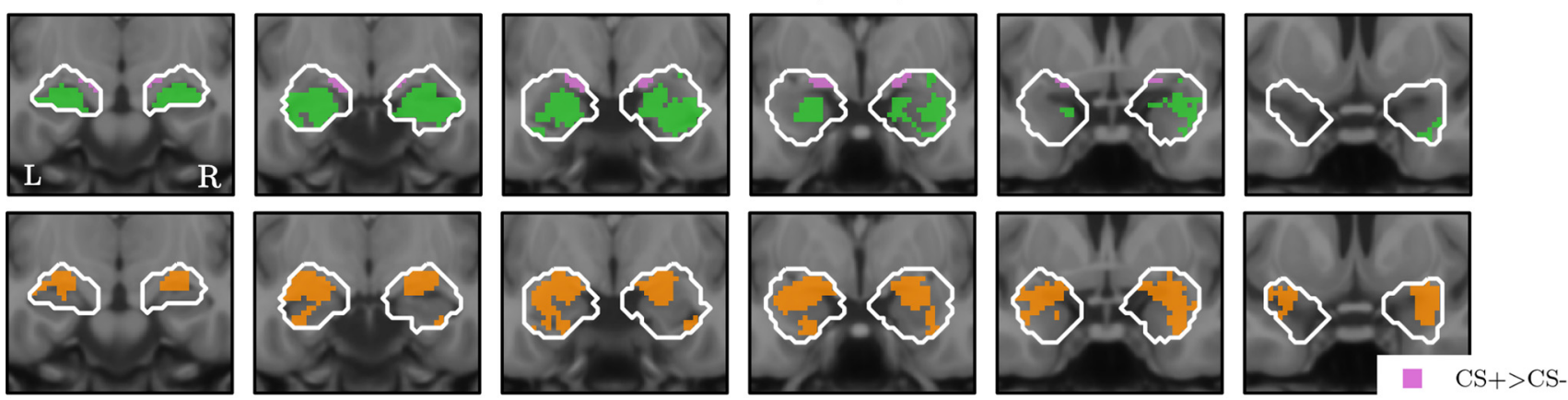

Extinction Learning $(\mathrm{n}=79)$
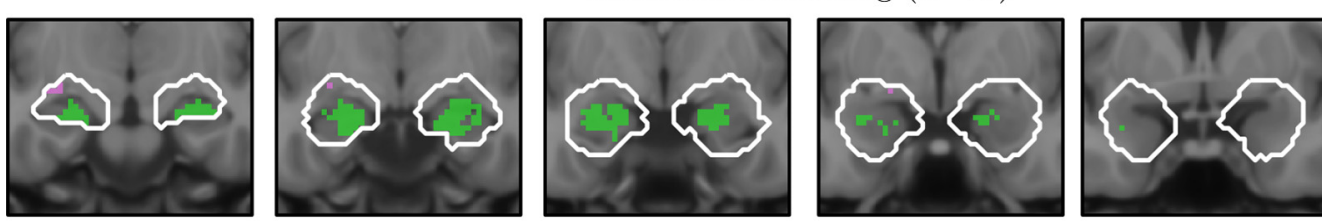

$\mathrm{CS}->\mathrm{CS}+$
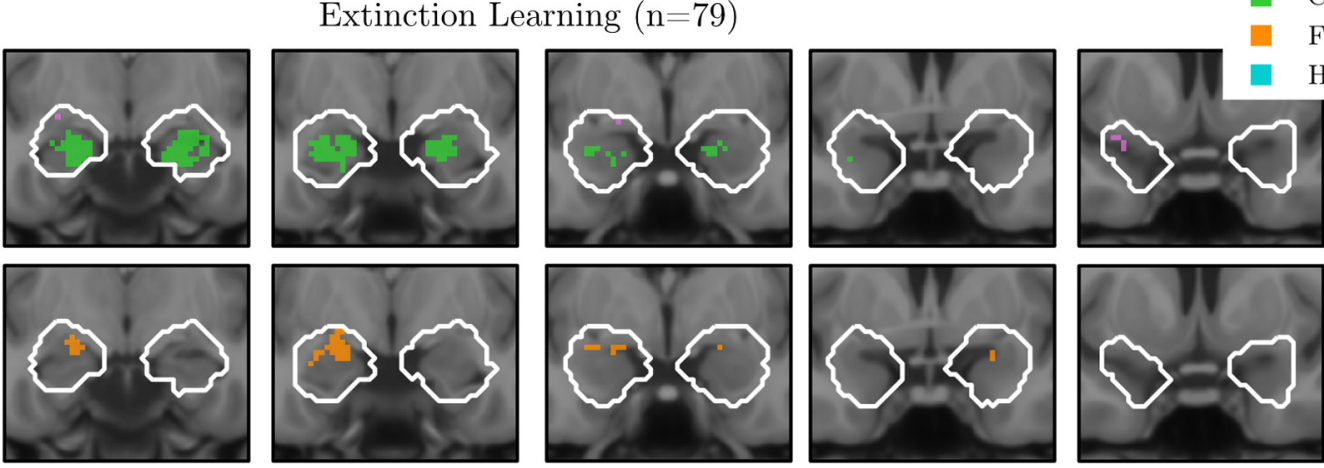

Amygdala Probability
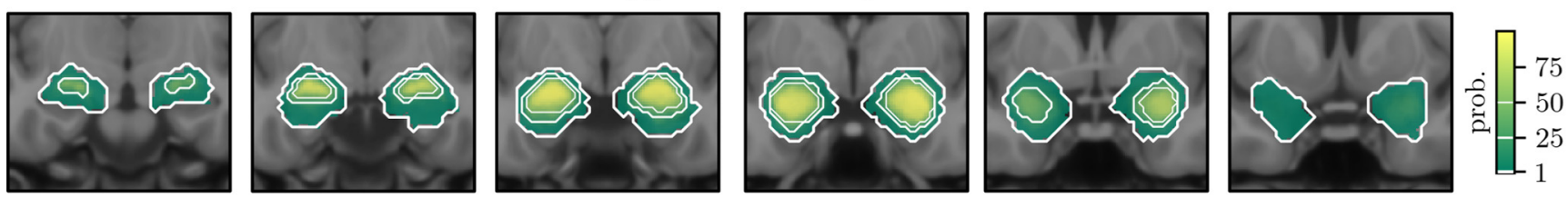

Susceptibility: Fear Acquisition $(n=98)$
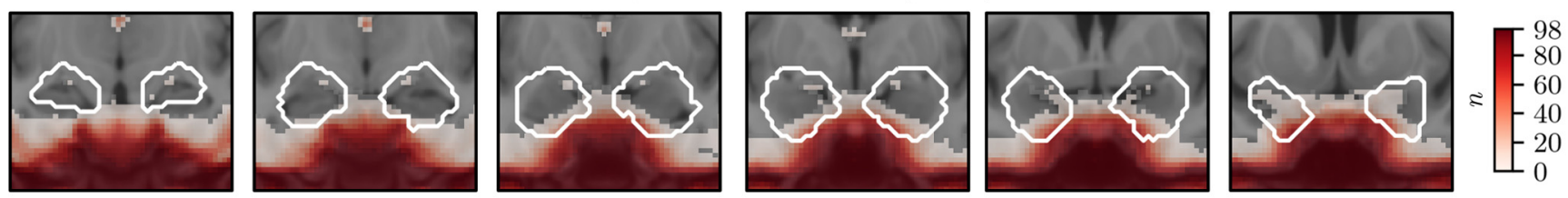

Susceptibility: Extinction Learning $(n=79)$

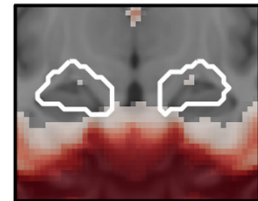

$y=-14$

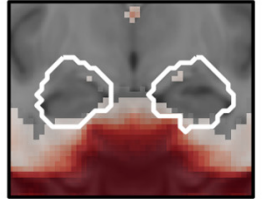

$\mathrm{y}=-10$

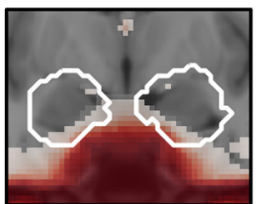

$y=-6$

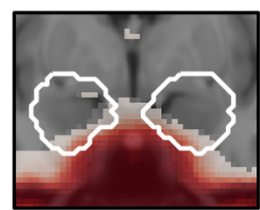

$y=-2$

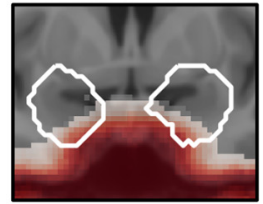

$y=2$

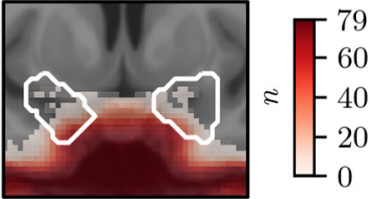

$\mathrm{y}=6$

Figure 2. Overview of the voxel-wise ROl analysis. Data were minimally spatially smoothed $(2 \mathrm{~mm})$. The top four rows show significant voxels (TFCE corrected, $p<0.05)$ within the amygdala mask (Harvard-0xford, thresholded at $p>0.01$ ), during fear acquisition (rows 1 and 2) and extinction learning (rows 3 and 4). The fifth row depicts the probabilistic R0l, with white outlines representing the different thresholds used to create binary masks. The bottom two rows depict the number of participants who had signal dropout in a particular voxel during fear acquisition and fear extinction. Coordinates refer to MNI space. L, Left; R, right.

Mean percentage signal change. In addition to the voxel-wise analyses, we averaged activity across voxels in the amygdala mask (at a liberal threshold of $p>0.01$ ), per condition $\left(\mathrm{CS}^{+}\right.$face, $\mathrm{CS}^{-}$face, $\mathrm{CS}^{+}$house, $\mathrm{CS}^{-}$house), per individual. Using SPSS (version 26; IBM), we examined the main effects of picture type (face/house), main effects of learned threat $\left(\mathrm{CS}^{+} / \mathrm{CS}^{-}\right)$, and an interaction of picture type $\times$ learned threat. In addition, we used a paired $t$ test to compare the average difference between face and house stimuli, averaged across CS type, to the average difference between $\mathrm{CS}^{+}$and $\mathrm{CS}^{-}$, averaged across picture type, to directly compare effects in both contrasts.

Whole-brain analysis. In addition to the ROI analysis, a voxel-wise whole-brain analysis was performed on data with moderate $(5 \mathrm{~mm})$ spatial smoothing. Regressors were modeled in a GLM as described in subsection Voxel-wise ROI analysis. We performed a permutation-based analysis with 5000 permutations and TFCE (Winkler et al., 2014), as implemented in FSL randomize across the whole brain.

\section{Results}

Conditioned pupil response

Pupil dilation responses were assessed as an independent measure of anticipatory arousal to verify that aversive conditioning was successful. As can be seen in Figure 1, fear 
Table 3. Number and percentage of significant voxels during fear acquisition $(n=98$, TFCE-corrected $p<0.05)$ within each mask, and MNI coordinates of local maxima

\begin{tabular}{|c|c|c|c|c|c|c|}
\hline & $\begin{array}{l}L \text { amygdala }(p>0.01) \\
\text { (1452 voxels) }\end{array}$ & $\begin{array}{l}R \text { amygdala }(p>0.01) \\
\text { (1623 voxels) }\end{array}$ & $\begin{array}{l}L \text { amygdala }(p>0.25) \\
(432 \text { voxels) }\end{array}$ & $\begin{array}{l}R \text { amygdala }(p>0.25) \\
\text { (492 voxels) }\end{array}$ & $\begin{array}{l}L \text { amygdala }(p>0.50) \\
(240 \text { voxels) }\end{array}$ & $\begin{array}{l}R \text { amygdala }(p>0.50) \\
\text { (280 voxels) }\end{array}$ \\
\hline \multicolumn{7}{|c|}{$\mathrm{CS}^{+}>\mathrm{CS}^{-}$} \\
\hline $2 \mathrm{~mm}$ & $\begin{array}{l}59(4.1 \%) \\
{[-16,-2,-10]^{a}}\end{array}$ & $\begin{array}{l}41(2.5 \%) \\
{[14,-14,-10]^{b}}\end{array}$ & 0 & 0 & 0 & 0 \\
\hline $5 \mathrm{~mm}$ & $\begin{array}{l}59(4.1 \%) \\
{[-14,-4,-10]^{c}}\end{array}$ & $\begin{array}{l}44(2.7 \%) \\
{[14,-14,-10]^{b}}\end{array}$ & 0 & 0 & 0 & 0 \\
\hline $8 \mathrm{~mm}$ & $\begin{array}{l}50(3.4 \%) \\
{[-14,-4,-10]^{c}}\end{array}$ & $\begin{array}{l}40(2.5 \%) \\
{[14,-14,-10]^{b}}\end{array}$ & 0 & 0 & 0 & 0 \\
\hline $2 \mathrm{~mm}$ & $\begin{array}{l}395(27.2 \%) \\
{[-20,-14,-18]^{d}}\end{array}$ & $\begin{array}{l}566(34.9 \%) \\
{[28,-16,-16]^{e}}\end{array}$ & $\begin{array}{l}187(43.4 \%) \\
{[-18,-10,-18]^{f}}\end{array}$ & $\begin{array}{l}249(50.6 \%) \\
{[16,-8,-20]^{9}}\end{array}$ & $\begin{array}{l}126(52.5 \%) \\
{[-22,-10,-16]^{h}}\end{array}$ & $\begin{array}{l}161(57.5 \%) \\
{[18,-8,-18]^{i}}\end{array}$ \\
\hline $5 \mathrm{~mm}$ & $\begin{array}{l}399(27.2 \%) \\
{[-20,-14,-20]^{j}}\end{array}$ & $\begin{array}{l}585(36.0 \%) \\
{[32,-16,-18]^{k}}\end{array}$ & $\begin{array}{l}181(41.9 \%) \\
{[-16,-8,-20]^{\prime}}\end{array}$ & $\begin{array}{l}248(50.4 \%) \\
{[30,-4,-24]^{m}}\end{array}$ & $\begin{array}{l}127(52.9 \%) \\
{[-18,-8,-18]^{n}}\end{array}$ & $\begin{array}{l}171(61.1 \%) \\
{[30,-4,-24]^{m}}\end{array}$ \\
\hline $8 \mathrm{~mm}$ & $\begin{array}{l}434(29.9 \%) \\
{[-20,-16,-18]^{0}}\end{array}$ & $\begin{array}{l}646(39.8 \%) \\
{[32,-16,-18]^{k}}\end{array}$ & $\begin{array}{l}192(44.4 \%) \\
{[-18,-8,-20]^{p}}\end{array}$ & $\begin{array}{l}278(56.5 \%) \\
{[30,-4,-24]^{m}}\end{array}$ & $\begin{array}{l}127(52.9 \%) \\
{[-22,-10,-16]^{h}}\end{array}$ & $\begin{array}{l}195(69.6 \%) \\
{[30,-4,-24]^{m}}\end{array}$ \\
\hline $8 \mathrm{~mm}$ & $\begin{array}{l}710(48.9 \%) \\
{[-20,-6,-14]^{5}}\end{array}$ & $\begin{array}{l}710(43.7 \%) \\
{[20,-6,-14]^{r}}\end{array}$ & $\begin{array}{l}340(78.8 \%) \\
{[-20,-6,-14]^{5}}\end{array}$ & $\begin{array}{l}321(65.2 \%) \\
{[20,-6,-14]^{r}}\end{array}$ & $\begin{array}{l}208(86.7 \%) \\
{[-20,-6,-14]^{5}}\end{array}$ & $\begin{array}{l}211(75.4 \%) \\
{[20,-6,-14]^{r}}\end{array}$ \\
\hline \multicolumn{7}{|c|}{ House $>$ face } \\
\hline $2 \mathrm{~mm}$ & 0 & 0 & 0 & 0 & 0 & 0 \\
\hline $5 \mathrm{~mm}$ & 0 & 0 & 0 & 0 & 0 & 0 \\
\hline $8 \mathrm{~mm}$ & 0 & 0 & 0 & 0 & 0 & 0 \\
\hline
\end{tabular}

Labels associated with local maxima are based on the Harvard-0xford probabilistic atlases. Some of the peak coordinates fall just outside the amygdala; because of resampling, the anatomical mask at the lowest threshold $(p>0.01)$ is slightly larger than the atlas indicates. L, Left; $R$, right.

${ }^{a} 53 \% \mathrm{~L}$ cerebral white matter, $27 \% \mathrm{~L}$ cerebral cortex, $10 \% \mathrm{~L}$ pallidum, $5 \% \mathrm{~L}$ amygdala.

${ }^{b} 21 \%$ R cerebral white matter.

$66 \% \mathrm{~L}$ cerebral white matter, 13\% L pallidum, 9\% L cerebral cortex, $2 \% \mathrm{~L}$ amygdala.

${ }^{d} 92 \% \mathrm{~L}$ hippocampus, 5\% L amygdala.

${ }^{e} 93 \% \mathrm{R}$ hippocampus, $1 \% \mathrm{R}$ amygdala.

f $58 \% \mathrm{~L}$ hippocampus, 39\% L amygdala.

${ }^{9} 63 \%$ R hippocampus, $28 \%$ R amygdala, 8\% R cerebral cortex.

${ }^{h} 64 \% \mathrm{~L}$ amygdala, $21 \% \mathrm{~L}$ hippocampus.

${ }^{i} 58 \% \mathrm{R}$ amygdala, $40 \% \mathrm{R}$ hippocampus.

$99 \% \mathrm{~L}$ hippocampus, 1\% L amygdala.

${ }^{k} 96 \%$ R hippocampus, $3 \%$ R cerebral white matter.

$58 \% \mathrm{~L}$ hippocampus, 35\% L amygdala, 6\% L cerebral cortex.

${ }^{m} 60 \% \mathrm{R}$ amygdala, $27 \% \mathrm{R}$ hippocampus, $5 \% \mathrm{R}$ cerebral white matter.

${ }^{n} 69 \% \mathrm{~L}$ amygdala, 30\% $\mathrm{L}$ hippocampus.

${ }^{95 \%} \mathrm{~L}$ hippocampus, $2 \% \mathrm{~L}$ amygdala, $1 \% \mathrm{~L}$ cerebral cortex.

${ }^{p} 55 \% \mathrm{~L}$ hippocampus, $44 \% \mathrm{~L}$ amygdala.

${ }^{9} 90 \% \mathrm{~L}$ amygdala, 3\% L cerebral white matter, $2 \% \mathrm{~L}$ cerebral cortex.

${ }^{r} 97 \% \mathrm{R}$ amygdala, $2 \% \mathrm{R}$ hippocampus, $1 \% \mathrm{R}$ cerebral cortex, $1 \% \mathrm{R}$ cerebral white matter.

${ }^{5} 97 \% \mathrm{~L}$ amygdala, $1 \% \mathrm{~L}$ cerebral cortex, $1 \% \mathrm{~L}$ cerebral white matter.

acquisition was evident from a trial-by-trial increase in pupil dilation in response to the $\mathrm{CS}^{+}$, relative to the $\mathrm{CS}^{-}$ $\left(F_{(12,900)}=23.59, p<0.001, \eta_{\mathrm{P}}^{2}=0.24\right)$, as well as a main effect of stimulus $\left(F_{(1,75)}=262.47, p<0.001, \eta_{\mathrm{P}}^{2}=0.78\right)$. During the extinction learning phase, average responses to the $\mathrm{CS}^{+}$were higher than to the $\mathrm{CS}^{-}\left(F_{(1,76)}=129.23\right.$, $\left.p<0.001, \eta_{\mathrm{P}}^{2}=0.63\right)$, and extinction of fear was evident from a decrease in pupil dilation in response to the $\mathrm{CS}^{+}$, relative to the $\mathrm{CS}^{-}\left(F_{(12,912)}=15.56, p<0.001, \eta_{\mathrm{P}}^{2}=0.17\right)$. This indicated that the fear acquisition and extinction learning procedures were successful.

\section{ROI results}

Voxel-wise amygdala ROI results (TFCE corrected, $p<0.05$ ) for fear acquisition and extinction learning are presented in Figure 2 (2 mm smoothing) and Tables 3 and 4 (2, 5, and $8 \mathrm{~mm}$ smoothing). Both during acquisition (Table 3 ) and extinction learning
(Table 4), a small cluster at the border of the superficial nucleus of the amygdala (with a higher probability of being WM or pallidum than amygdala) showed higher activation in response to the $\mathrm{CS}^{+}$compared with the $\mathrm{CS}^{-}$(purple). When thresholding the amygdala masks at $p>0.25$, no significant voxels remained (Tables 3, 4). In contrast, and as expected, robust responses to faces (averaged over $\mathrm{CS}^{+}$and $\mathrm{CS}^{-}$) compared with houses (averaged over $\mathrm{CS}^{+}$and $\mathrm{CS}^{-}$) were observed in large parts of the amygdala (up to $75 \%$ of the voxels within the mask thresholded at $p>0.5$; Tables 3,4$)$.

Unexpectedly, the amygdala showed much stronger responses to the $\mathrm{CS}^{-}$compared with the $\mathrm{CS}^{+}$(Tables 3, 4). Further inspection suggested that some of the signal originated from the anterior hippocampus/amygdala-hippocampus transition area, which is in line with other studies (Fullana et al., 2016), though a substantial part of the signal seemed to originate from the basolateral part of the amygdala. 
Table 4. Number and percentage of significant voxels during fear extinction learning $(n=79$, TFCE-corrected $p<0.05)$ within each mask, and MNI coordinates of local maxima

\begin{tabular}{|c|c|c|c|c|c|c|}
\hline & $\begin{array}{l}\text { L amygdala }(p>0.01) \\
\text { (1452 voxels) }\end{array}$ & $\begin{array}{l}R \text { amygdala }(p>0.01) \\
(1623 \text { voxels) }\end{array}$ & $\begin{array}{l}L \text { amygdala }(p>0.25) \\
\text { (432 voxels) }\end{array}$ & $\begin{array}{l}R \text { amygdala }(p>0.25) \\
\text { (492 voxels) }\end{array}$ & $\begin{array}{l}\text { L amygdala }(p>0.50) \\
(240 \text { voxels) }\end{array}$ & $\begin{array}{l}R \text { amygdala }(p>0.50) \\
(280 \text { voxels) }\end{array}$ \\
\hline \multicolumn{7}{|c|}{$\mathrm{CS}^{+}>\mathrm{CS}^{-}$} \\
\hline $2 \mathrm{~mm}$ & $\begin{array}{l}15(1.0 \%) \\
{[-28,-14,-10]^{a}} \\
5(0.3 \%) \\
{[-28,6,-18]^{b}} \\
1(0.1 \%) \\
{[-18,-2,-10]^{c}}\end{array}$ & 0 & 0 & 0 & 0 & 0 \\
\hline $5 \mathrm{~mm}$ & $\begin{array}{l}22(1.5 \%) \\
{[-30,6,-14]^{d}} \\
14(1.0 \%) \\
{[-30,-16,-10]^{e}}\end{array}$ & 0 & 0 & 0 & 0 & 0 \\
\hline $8 \mathrm{~mm}$ & $\begin{array}{l}29(2.0 \%) \\
{[-32,6,-16]^{f}} \\
4(0.3 \%) \\
{[-30,-16,-10]^{e}}\end{array}$ & 0 & 0 & 0 & 0 & 0 \\
\hline \multicolumn{7}{|c|}{$\mathrm{CS}^{-}>\mathrm{CS}^{+}$} \\
\hline $2 \mathrm{~mm}$ & $\begin{array}{l}193(13.3 \%) \\
{[-18,-12,-22]^{g}}\end{array}$ & $\begin{array}{l}157(9.7 \%) \\
{[22,-10,-16]^{h}}\end{array}$ & $\begin{array}{l}137(31.7 \%) \\
{[-18,-8,-20]^{i}}\end{array}$ & $\begin{array}{l}77(15.7 \%) \\
{[22,-10,-16]^{h}}\end{array}$ & $\begin{array}{l}106(44.2 \%) \\
{[-16,-6,-20]^{j}}\end{array}$ & $\begin{array}{l}55(19.6 \%) \\
{[22,-6,-20]^{k}}\end{array}$ \\
\hline $5 \mathrm{~mm}$ & $\begin{array}{l}215(14.8 \%) \\
{[-18,-12,-22]^{g}}\end{array}$ & $\begin{array}{l}147(9.1 \%) \\
{[22,-8,-16]^{\prime}}\end{array}$ & $\begin{array}{l}136(31.5 \%) \\
{[-16,-8,-20]^{m}}\end{array}$ & $\begin{array}{l}67(13.6 \%) \\
{[22,-8,-16]^{\prime}}\end{array}$ & $\begin{array}{l}105(43.8 \%) \\
{[-28,-4,-20]^{n}}\end{array}$ & $\begin{array}{l}50(17.9 \%) \\
{[22,-8,-16]^{\prime}}\end{array}$ \\
\hline $8 \mathrm{~mm}$ & $\begin{array}{l}197(13.6 \%) \\
{[-18,-12,-22]^{9}}\end{array}$ & $\begin{array}{l}132(8.1 \%) \\
{[20,-8,-20]^{0}}\end{array}$ & $\begin{array}{l}140(32.4 \%) \\
{[-20,-6,-22]^{p}}\end{array}$ & $\begin{array}{c}61(12.4 \%) \\
{[20,-8,-20]^{0}}\end{array}$ & $\begin{array}{l}100(41.7 \%) \\
{[-20,-6,-22]^{p}}\end{array}$ & $\begin{array}{l}42(15.0 \%) \\
{[20,-6,-20]^{k}}\end{array}$ \\
\hline \multicolumn{7}{|c|}{ Face $>$ house } \\
\hline $2 \mathrm{~mm}$ & $\begin{array}{l}81(5.6 \%) \\
{[-18,-8,-14]^{q}}\end{array}$ & $\begin{array}{c}21(1.3 \%) \\
{[28,-16,-12]^{r}} \\
3(0.1 \%) \\
{[24,2,-18]^{s}} \\
1(0.1 \%) \\
{[20,-2,-14]^{t}} \\
1(0.1 \%) \\
{[12,-4,-10]^{u}}\end{array}$ & $\begin{array}{l}114(26.4 \%) \\
{[-18,-8,-14]^{9}}\end{array}$ & $\begin{array}{c}28(5.7 \%) \\
{[24,2,-18]^{s}} \\
3(0.6 \%) \\
{[26,-14,-12]^{v}}\end{array}$ & $\begin{array}{l}103(42.9 \%) \\
{[-18,-8,-14]^{q}}\end{array}$ & $\begin{array}{l}23(8.2 \%) \\
{[24,2,-18]^{5}}\end{array}$ \\
\hline $5 \mathrm{~mm}$ & $\begin{array}{l}69(4.8 \%) \\
{[-20,-8,-14]^{\omega}}\end{array}$ & $\begin{array}{l}96(5.9 \%) \\
{[30,-18,-10]^{x}}\end{array}$ & $\begin{array}{l}112(25.9 \%) \\
{[-20,-8,-14]^{w}}\end{array}$ & $\begin{array}{c}91(18.5 \%) \\
{[24,2,-18]^{5}}\end{array}$ & $\begin{array}{l}105(43.8 \%) \\
{[-20,-8,-14]^{\mathrm{w}}}\end{array}$ & $\begin{array}{l}67(23.9 \%) \\
{[24,2,-18]^{5}}\end{array}$ \\
\hline $8 \mathrm{~mm}$ & $\begin{array}{l}70(4.8 \%) \\
{[-20,-8,-14]^{w}}\end{array}$ & $\begin{array}{l}70(4.3 \%) \\
{[20,-2,-10]^{y}} \\
41(2.5 \%) \\
{[30,-16,-12]^{2}} \\
1(0.1 \%) \\
{[24,-8,-16]^{a a}}\end{array}$ & $\begin{array}{l}128(29.6 \%) \\
{[-20,-8,-14]^{w}}\end{array}$ & $\begin{array}{l}100(20.3 \%) \\
{[20,-2,-12]^{b b}}\end{array}$ & $\begin{array}{l}126(52.5 \%) \\
{[-20,-8,-14]^{w}}\end{array}$ & $\begin{array}{l}77(27.5 \%) \\
{[20,-2,-12]^{b b}}\end{array}$ \\
\hline \multicolumn{7}{|c|}{ House $>$ face } \\
\hline $2 \mathrm{~mm}$ & 0 & 0 & 0 & 0 & 0 & 0 \\
\hline $5 \mathrm{~mm}$ & 0 & 0 & 0 & 0 & 0 & 0 \\
\hline $8 \mathrm{~mm}$ & 0 & 0 & 0 & 0 & 0 & 0 \\
\hline
\end{tabular}

Labels associated with local maxima are based on the Harvard-0xford probabilistic atlas. Some of the peak coordinates fall just outside the amygdala, because - because of resampling - the anatomical mask at the lowest threshold $(p>0.01)$ is slightly larger than the atlas indicates. R, Right; L, left.

${ }^{a} 71 \% \mathrm{~L}$ cerebral white matter, $17 \% \mathrm{~L}$ putamen, $6 \% \mathrm{~L}$ amygdala, $3 \% \mathrm{~L}$ hippocampus, $1 \% \mathrm{~L}$ pallidum.

${ }^{b} 78 \% \mathrm{~L}$ cerebral cortex, $2 \% \mathrm{~L}$ amygdala.

' $51 \% \mathrm{~L}$ cerebral white matter, $32 \% \mathrm{~L}$ cerebral cortex, $7 \% \mathrm{~L}$ amygdala, $7 \% \mathrm{~L}$ pallidum.

d $77 \% \mathrm{~L}$ cerebral cortex, $20 \% \mathrm{~L}$ cerebral white matter.

${ }^{e} 74 \% \mathrm{~L}$ cerebral white matter, 19\% L putamen, 4\% L hippocampus, 1\% L amygdala.

${ }_{8}^{f} 82 \% \mathrm{~L}$ cerebral cortex, $8 \% \mathrm{~L}$ cerebral white matter, $1 \% \mathrm{~L}$ amygdala.

${ }^{9} 87 \% \mathrm{~L}$ hippocampus, $9 \% \mathrm{~L}$ cerebral cortex, $3 \% \mathrm{~L}$ cerebral white matter, $1 \% \mathrm{~L}$ amygdala.

${ }^{h} 47 \% \mathrm{R}$ amygdala, 34\% R hippocampus.

${ }^{i} 55 \% \mathrm{~L}$ hippocampus, $44 \% \mathrm{~L}$ amygdala.

${ }^{j} 63 \% \mathrm{~L}$ amygdala, 33\% L hippocampus, 3\% L cerebral cortex.

${ }^{k} 74 \% \mathrm{R}$ amygdala, $25 \% \mathrm{R}$ hippocampus.

$77 \% \mathrm{R}$ amygdala, $14 \% \mathrm{R}$ hippocampus.

${ }^{m} 58 \% \mathrm{~L}$ hippocampus, $35 \% \mathrm{~L}$ amygdala, $6 \% \mathrm{~L}$ cerebral cortex.

${ }^{n} 96 \% \mathrm{~L}$ amygdala, 3\% L hippocampus, $1 \% \mathrm{~L}$ cerebral white matter, $1 \% \mathrm{~L}$ cerebral cortex.

${ }^{\circ} 64 \% \mathrm{R}$ hippocampus, 34\% R amygdala.

${ }^{p} 60 \% \mathrm{~L}$ amygdala, $40 \% \mathrm{~L}$ hippocampus.

${ }^{9} 92 \% \mathrm{~L}$ amygdala, $4 \% \mathrm{~L}$ cerebral white matter, $1 \% \mathrm{~L}$ hippocampus.

${ }^{r} 40 \% \mathrm{R}$ hippocampus, $21 \% \mathrm{R}$ cerebral white matter, $11 \% \mathrm{R}$ amygdala,

${ }^{s} 67 \% \mathrm{R}$ amygdala, $21 \% \mathrm{R}$ cerebral cortex, $0 \%$ Right cerebral white matter.

${ }^{t} 72 \% \mathrm{R}$ amygdala, $17 \% \mathrm{R}$ cerebral cortex, $2 \%$ Right cerebral white matter.

" $64 \% \mathrm{R}$ cerebral white matter, 9\% Right pallidum, $3 \% \mathrm{R}$ cerebral cortex.

${ }^{v} 31 \% R$ amygdala, $20 \% R$ cerebral white matter, $17 \%$ R hippocampus.

${ }^{w} 96 \% \mathrm{~L}$ amygdala, $1 \% \mathrm{~L}$ cerebral white matter, $1 \% \mathrm{~L}$ hippocampus.

${ }^{x} 65 \%$ R cerebral white matter, $24 \% \mathrm{R}$ hippocampus, $2 \% \mathrm{R}$ amygdala.

y $45 \% \mathrm{R}$ cerebral white matter, $25 \% \mathrm{R}$ cerebral cortex, $25 \% \mathrm{R}$ amygdala, $4 \% \mathrm{R}$ pallidum.

${ }^{z} 41 \%$ R cerebral white matter, 39\% R hippocampus, 6\% R amygdala.

${ }^{a a} 76 \% \mathrm{R}$ amygdala, $12 \% \mathrm{R}$ hippocampus.

${ }^{b b} 50 \% R$ amygdala, $30 \%$ R cerebral cortex, $13 \%$ R cerebral white matter, $2 \% R$ pallidum. 

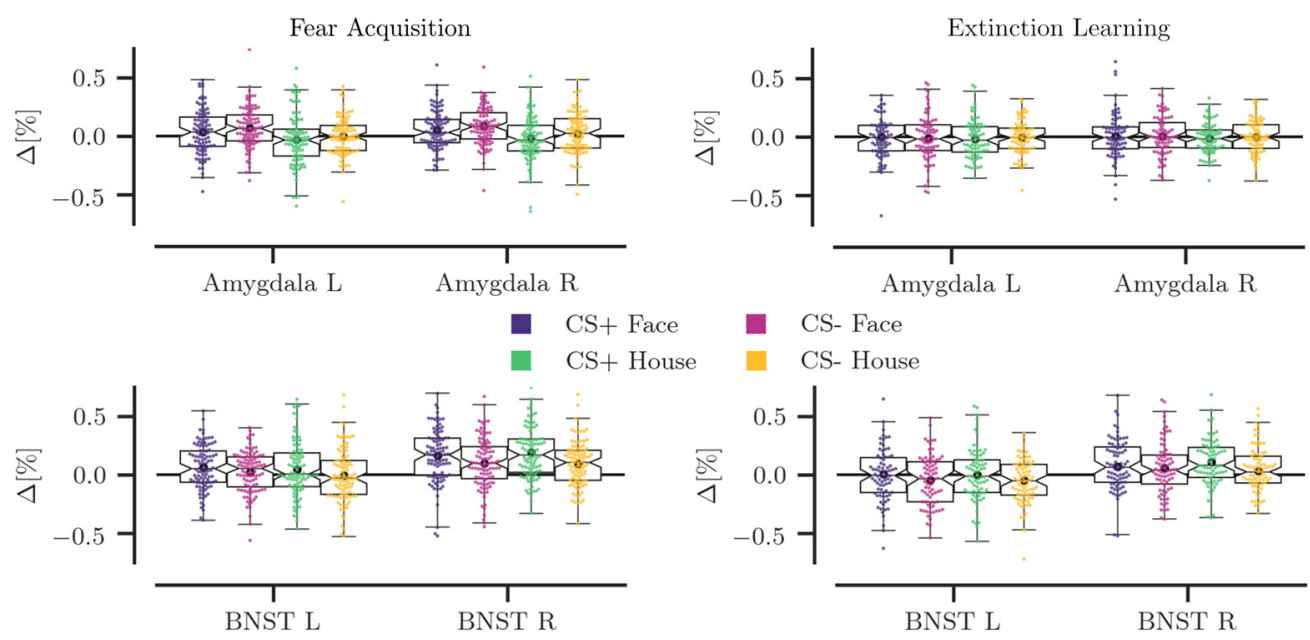

Figure 3. Overview of the ROl analysis of the mean signal change during fear acquisition and extinction learning. The top graph depicts the signal change per individual in the left and right amygdala per condition, and the bottom graph shows signal change per individual in the left and right BNST. During fear acquisition, amygdala responses are stronger to faces than to houses, and stronger to the $\mathrm{CS}^{-}$than the $\mathrm{CS}^{+}$, while no significant differences were observed during extinction learning. In contrast, the BNST shows typical threat anticipation with higher responses to the $C S^{+}$than the $C S^{-}$during both experimental phases. L, Left; $R$, right.

To examine signal dropout more directly, Figure 2 also depicts the number of participants who had signal dropout in a particular voxel during fear acquisition and fear extinction. All participants showed adequate signal in the amygdala mask thresholded at $p>0.5$. Some participants had dropout in regions with a low probability of being part of the amygdala nuclei. To estimate the impact of signal dropout, we repeated the voxelwise ROI analysis while excluding any participants with $>5 \%$ dropout in left and/or right amygdala ( $n=12$ for acquisition; $n=7$ for extinction). This did not change the pattern of results (parametric maps available on OSF; https://osf.io/cq5zr/). In sum, from the voxel-wise ROI analyses it is evident that a reliable signal was measured in the amygdala, and that the absence of robust responses to learned threat cannot be attributed to a poor signal.

In addition to these voxel-wise analyses, we averaged activity at the ROI level (mask thresholded at $p>0.01$ ) per condition, per individual, to directly compare the difference between face and house and $\mathrm{CS}^{+}$and $\mathrm{CS}^{-}$(Fig. 3). During fear acquisition, a main effect of picture type confirmed that faces elicited significantly more activation than houses in the left amygdala $\left(F_{(1,97)}=21.08\right.$, $\left.p<0.001, \quad \eta_{\mathrm{P}}^{2}=0.18\right)$ and right amygdala $\left(F_{(1,97)}=21.16\right.$, $\left.p<0.001, \eta_{\mathrm{P}}^{2}=0.18\right)$. In the left amygdala, the difference between $\mathrm{CS}^{+}$and $\mathrm{CS}^{-}$was not significant $\left(F_{(1,97)}=2.79, p=0.098, \eta_{\mathrm{P}}^{2}=\right.$ 0.03 ), while in the right amygdala the $\mathrm{CS}^{-}$evoked more activation than the $\mathrm{CS}^{+}\left(F_{(1,97)}=6.82, p=0.010, \eta_{\mathrm{P}}^{2}=0.07\right)$. There was also no significant interaction between learned threat and picture type ( $p$ values $>0.759$ ). A direct comparison of the positive differences between face and house stimuli in left (mean $=0.069, \mathrm{SD}=0.148$ ) and right (mean $=0.065, \mathrm{SD}=0.140$ ) amygdala with the negative differences between $\mathrm{CS}^{+}$and $\mathrm{CS}^{-}$in left (mean $=-0.031$, $\mathrm{SD}=0.182)$ and right (mean $=-0.041, \mathrm{SD}=0.155)$ amygdala revealed a significant difference $\left(t_{(97)}=3.57, p=0.001\right.$; and $t_{(97)}=4.35, p<0.001$, respectively). Notably, during extinction learning, there were no main effects of picture type, main effects of threat, or interactions between picture type and threat (all $p$ values $>0.386$ ). This tentatively suggests that the amygdala mainly favors social information (faces), and potentially safety information $\left(\mathrm{CS}^{-}\right)$, when it is novel (Blackford et al., 2010, 2013).

Interestingly, results in the BNST, which is part of the "extended amygdala" circuitry (Shackman and Fox, 2016), did show the expected conditioning effects, with stronger responses to $\mathrm{CS}^{+}$compared with $\mathrm{CS}^{-}$stimuli (Fig. 3$)$, in left $\left(F_{(1,97)}=6.23\right.$, $\left.p=0.014, \eta_{\mathrm{P}}^{2}=0.06\right)$ and right $\left(F_{(1,97)}=18.61, p<0.001, \eta_{\mathrm{P}}^{2}=\right.$ $0.16)$ BNST. This is in line with other large-scale studies of fear conditioning (Klumpers et al., 2017) and threat anticipation (Hur et al., 2020). During extinction, the difference between $\mathrm{CS}^{+}$ compared with $\mathrm{CS}^{-}$stimuli was still significant in the left BNST $\left(F_{(1,78)}=4.45, p=0.038, \eta_{\mathrm{P}}^{2}=0.05\right)$, and marginally significant in the right $\operatorname{BNST}\left(F_{(1,78)}=3.76, p=0.056, \eta_{\mathrm{P}}^{2}=0.05\right)$.

\section{Whole-brain results}

To allow comparison with previous meta-analyses, whole-brain results for the contrast $\mathrm{CS}^{+}$versus $\mathrm{CS}^{-}$are displayed in Figure 4 and summarized in Table 5. Compared with the $\mathrm{CS}^{-}$, the $\mathrm{CS}^{+}$ elicited more activation in areas corresponding to the salience network, including the thalamus, brainstem, striatum, temporoparietal junction, anterior insula (extending to frontal opercular and frontal orbital cortex), and a large cluster centered around the midcingulate cortex (following nomenclature by Vogt and Paxinos, 2014; van Heukelum et al., 2020; in the human fearlearning literature, it is most commonly referred to as "dorsal anterior cingulate"), extending to the anterior cingulate cortex and the superior frontal gyrus, both during fear acquisition and fear extinction learning. These results are in line with previous metaanalyses on fear acquisition (Mechias et al., 2010; Fullana et al., 2016) and extinction learning (Fullana et al., 2018). The reverse contrast primarily showed activation in the hippocampus extending into the posterior parts of the amygdala, and occipital and temporal areas, and a cluster at the intersection of frontal pole and medial prefrontal cortex.

Whole-brain results for the face versus house contrast are displayed in Figure 4 and summarized in Table 6. Typical activation is seen in the fusiform face area (located in the temporal occipital fusiform cortex), in response to faces (Kanwisher et al., 1997), and in the parahippocampal place area (located in the posterior division of the parahippocampal gyrus) in response to houses (Epstein and Kanwisher, 1998). Notably, during fear acquisition a large cluster of activation in the amygdala was observed in response to faces compared with houses, in a region overlapping with coordinates previously reported in the context of learned threat (Sjouwerman et al., 2020) and other forms of certain threat anticipation (Hur et al., 


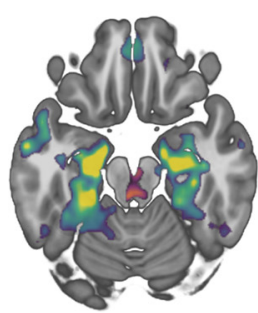

$\mathrm{L}$

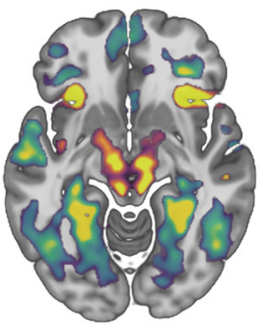

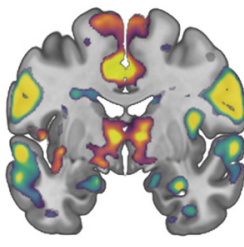

$\mathrm{CS}+>\mathrm{CS}-$

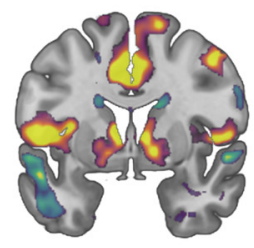

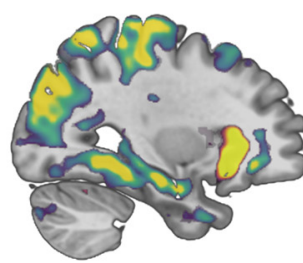

CS- $>$ CS +
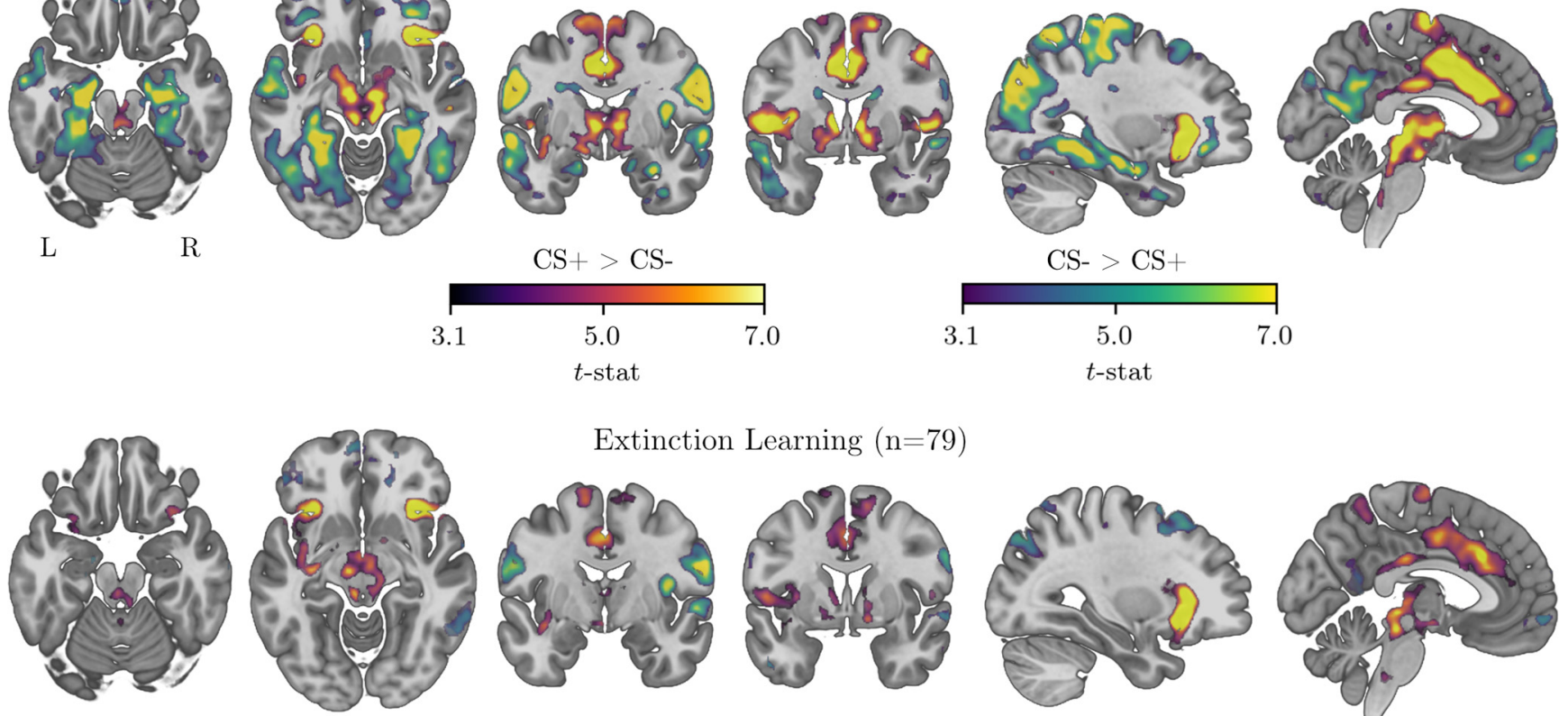

Extinction Learning $(\mathrm{n}=79)$
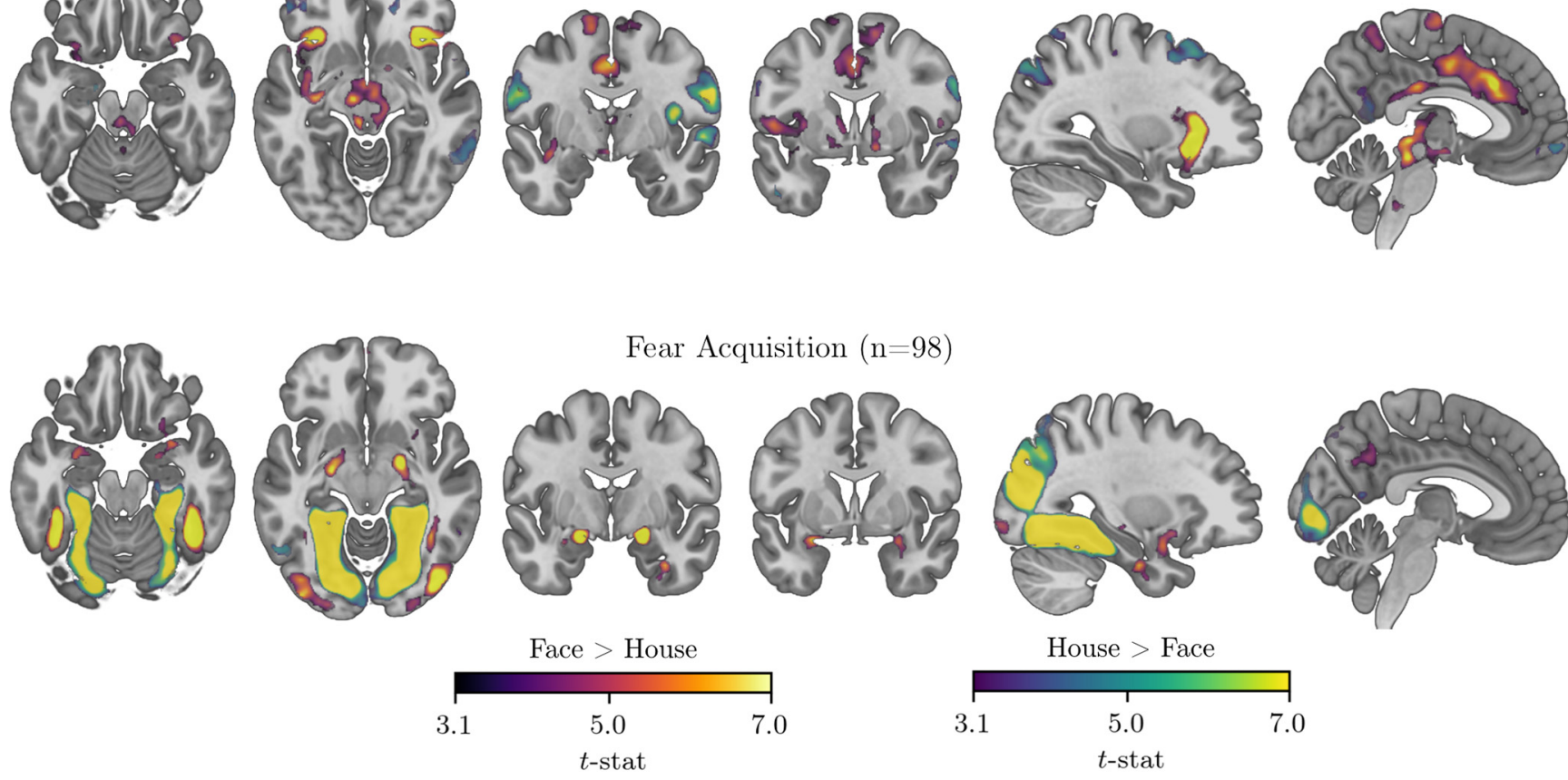

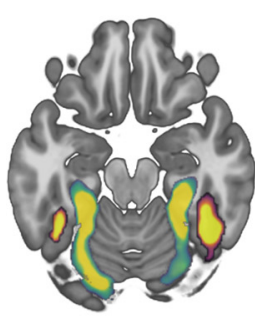

$\mathrm{z}=-20$

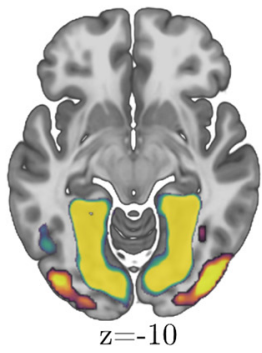

Extinction Learning $(\mathrm{n}=79)$
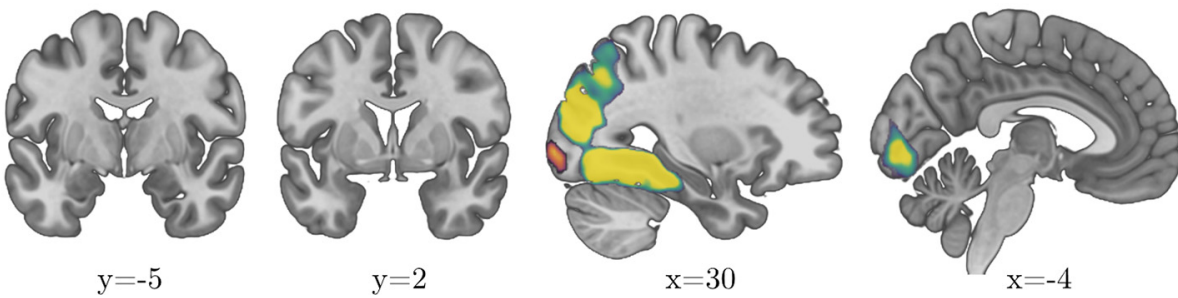

Figure 4. Whole-brain results for the $\mathrm{CS}^{+}$versus $\mathrm{CS}^{-}$contrast (top rows), and the face versus house contrast (bottom rows), during fear acquisition and extinction learning (TFCE corrected, $p<0.05)$. Results for the $\mathrm{CS}^{+}>\mathrm{CS}^{-}$comparison and for the face $>$house comparison appear in purple/orange/yellow colors. Results for the $\mathrm{CS}^{-}>\mathrm{CS}^{+}$comparison and for the house $>$ face comparison are shown in blue/green/yellow colors.

2020). During extinction learning, activation in the amygdala did not reach significance (only in voxel-wise ROI analyses, Table 4), suggesting an interaction of socially relevant information and novelty (Blackford et al., 2010, 2013).

\section{Relation between amygdala and indices of fear}

Average trait anxiety in our sample, as measured by the StateTrait Anxiety Inventory-Trait version (STAI-T; Table 1), was comparable to average trait anxiety in a recent large-sample imaging study (Sjouwerman et al., 2020). As trait anxiety has been reported to covary with amygdala activation in Pavlovian conditioning (Sjouwerman et al., 2020), we entered demeaned scores on the STAI-T as a separate predictor in our voxel-wise amygdala analysis (probability threshold, $p>0.01$ ). No significant voxels were found (parametric map for this control analysis available on OSF; https://osf.io/cq5zr/).

In many fear-conditioning studies, participants are excluded if they do not show evidence of learning as assessed by an independent measure, such as skin conductance or pupil dilation. The use of idiosyncratic criteria to define such "non-learners" has been criticized (Lonsdorf et al., 2019), and poses problems for replication studies. The definition of nonlearners on the basis 
Table 5. Brain areas showing differential activation for the contrast $\mathrm{CS}^{+}$versus $\mathrm{CS}^{-}$

\begin{tabular}{|c|c|c|c|c|c|}
\hline \multirow[b]{2}{*}{ Brain region (COG) } & \multicolumn{3}{|c|}{ MNI coordinates } & \multirow[b]{2}{*}{ Volume (voxels) } & \multirow[b]{2}{*}{ Maximum z } \\
\hline & $x$ & $y$ & $z$ & & \\
\hline \multicolumn{6}{|l|}{$\mathrm{CS}^{+}>\mathrm{CS}^{-}$} \\
\hline $\begin{array}{l}\mathrm{L} \text { and } \mathrm{R} \text { cingulate gyrus, anterior division (midcingulate cortex)/paracingulate cortex/superior frontal gyrus/cingulate gyrus, } \\
\text { posterior division/juxtapositional lobule }\end{array}$ & -4 & 22 & 24 & 6904 & 9.3 \\
\hline$L$ and $R$ caudate/thalamus/brainstem & -8 & 8 & 4 & 4313 & 8.9 \\
\hline L parietal operculum cortex/supramarginal gyrus & -56 & -30 & 22 & 844 & 8.81 \\
\hline R supramarginal gyrus/angular gyrus & 62 & -44 & 24 & 464 & 8.24 \\
\hline L superior parietal lobule/postcentral gyrus & -20 & -50 & 72 & 434 & 6.55 \\
\hline $\mathrm{R}$ inferior frontal gyrus/middle frontal gyrus & 38 & 14 & 26 & 262 & 4.71 \\
\hline $\mathrm{R}$ precentral gyrus/middle frontal gyrus & 46 & 2 & 50 & 257 & 6.88 \\
\hline R parietal operculum cortex /supramarginal gyrus, anterior division & 54 & -26 & 26 & 210 & 7.46 \\
\hline L frontal orbital cortex/anterior insular cortex/frontal operculum cortex/precentral gyrus & -32 & 24 & -6 & 2266 & 8.64 \\
\hline R frontal orbital cortex/anterior insular cortex/frontal operculum cortex/precentral gyrus/inferior frontal gyrus & 34 & 24 & -6 & 2136 & 10.6 \\
\hline $\mathrm{L}$ and $\mathrm{R}$ brainstem/thalamus & -4 & -30 & -14 & 1667 & 6.59 \\
\hline L superior parietal lobule & -20 & -50 & 72 & 962 & 7.25 \\
\hline L parietal operculum cortex/supramarginal gyrus & -58 & -34 & 26 & 530 & 8.44 \\
\hline L superior frontal gyrus/juxtapositional lobule & -12 & -10 & 72 & 490 & 5.71 \\
\hline $\mathrm{R}$ parietal operculum cortex/supramarginal gyrus & 54 & -26 & 26 & 398 & 5.92 \\
\hline L caudate & -6 & 8 & 2 & 207 & 6.08 \\
\hline Brainstem & 0 & -38 & -34 & 108 & 5.3 \\
\hline $\mathrm{R}$ cerebellum & 42 & -54 & -30 & 54 & 4.49 \\
\hline $\mathrm{R}$ lingual gyrus & 2 & -64 & -4 & 44 & 5.41 \\
\hline$R$ precuneus cortex & 8 & -52 & 64 & 13 & 3.53 \\
\hline \multicolumn{6}{|l|}{$\mathrm{CS}^{-}>\mathrm{CS}^{+}$} \\
\hline R cerebellum & 22 & -86 & -38 & 323 & 5.21 \\
\hline L frontal orbital cortex/frontal pole & -40 & 30 & -14 & 312 & 6.23 \\
\hline R temporal fusiform cortex/temporal pole & 38 & -8 & -38 & 238 & 5.53 \\
\hline R frontal pole & 38 & 38 & 18 & 140 & 4.61 \\
\hline $\mathrm{L}$ inferior frontal gyrus/white matter & -28 & 24 & 18 & 122 & 4.47 \\
\hline L frontal pole & -46 & 44 & 6 & 81 & 4.07 \\
\hline $\mathrm{L}$ and $\mathrm{R}$ subcallosal cortex & 2 & 22 & -10 & 76 & 4.65 \\
\hline L cerebellum & -8 & -72 & -46 & 74 & 3.99 \\
\hline L white matter & -10 & 26 & 4 & 43 & 3.76 \\
\hline L frontal pole & -22 & 50 & -6 & 33 & 4.64 \\
\hline R temporal pole & 34 & 22 & -32 & 32 & 4.09 \\
\hline $\mathrm{R}$ white matter & 34 & -38 & 24 & 26 & 3.85 \\
\hline L precentral gyrus & -8 & -22 & 50 & 23 & 4.31 \\
\hline L superior frontal gyrus & -20 & -12 & 50 & 19 & 3.93 \\
\hline White matter & 0 & 4 & 20 & 18 & 4.08 \\
\hline $\mathrm{R}$ cerebellum & 20 & -62 & -44 & 16 & 4.01 \\
\hline L parahippocampal gyrus & -20 & 0 & -40 & 15 & 4.53 \\
\hline L white matter & -18 & 36 & -2 & 14 & 3.61 \\
\hline$L$ middle frontal gyrus & -44 & 12 & 38 & 12 & 3.89 \\
\hline L superior frontal gyrus & -22 & -6 & 60 & 11 & 3.62 \\
\hline $\mathrm{R}$ frontal pole & 16 & 42 & 36 & 11 & 3.53 \\
\hline \multicolumn{6}{|l|}{ Extinction $(n=79)$} \\
\hline R postcentral gyrus/precentral gyrus/superior parietal lobule/supramarginal gyrus & 60 & -6 & 24 & 2377 & 6.72 \\
\hline L postcentral gyrus/precentral gyrus/superior parietal lobule/supramarginal gyrus/central opercular cortex & -54 & -8 & 26 & 1561 & 6.11 \\
\hline
\end{tabular}




\begin{tabular}{|c|c|c|c|c|c|}
\hline \multirow[b]{2}{*}{ Brain region $(\mathrm{COG})$} & \multicolumn{3}{|c|}{ MNI coordinates } & \multirow[b]{2}{*}{ Volume (voxels) } & \multirow[b]{2}{*}{ Maximum $z$} \\
\hline & $x$ & $y$ & $z$ & & \\
\hline L middle frontal gyrus/superior frontal gyrus & -32 & 16 & 60 & 813 & 5.19 \\
\hline L lateral occipital cortex, superior division & -30 & -74 & 30 & 655 & 4.36 \\
\hline L middle frontal gyrus/inferior frontal gyrus & -52 & 28 & 26 & 643 & 5.1 \\
\hline L frontal pole & -8 & 60 & -8 & 345 & 4.73 \\
\hline $\mathrm{R}$ central opercular cortex/insula cortex & 42 & -8 & 16 & 245 & 8.55 \\
\hline L precuneus cortex & -8 & -54 & 16 & 195 & 5 \\
\hline L frontal pole & -8 & 66 & 20 & 78 & 4.89 \\
\hline L temporal pole & -48 & 2 & -38 & 40 & 4.73 \\
\hline R temporal pole & 46 & 18 & -36 & 37 & 4.17 \\
\hline L hippocampus & -18 & -12 & -22 & 35 & 5.44 \\
\hline R postcentral gyrus & 44 & -38 & 66 & 21 & 3.93 \\
\hline R middle temporal gyrus, posterior division & 70 & -14 & -16 & 19 & 4.18 \\
\hline R precentral gyrus & 26 & -26 & 50 & 16 & 3.57 \\
\hline L lateral occipital cortex, superior division & -26 & -86 & 20 & 15 & 3.46 \\
\hline R middle temporal gyrus, anterior division & 52 & 0 & -32 & 15 & 3.98 \\
\hline L temporal pole & -48 & 14 & -30 & 12 & 5.06 \\
\hline
\end{tabular}

Whole-brain activation (TFCE corrected, $p<0.05$ ) that discriminates the threat-associated $\left(\mathrm{CS}^{+}\right)$stimuli from the control stimuli $\left(\mathrm{CS}^{-}\right)$. Coordinates are in MNI space and indicate the voxel with the highest $z$ value, for each significant cluster. Minimum cluster size reported here: $k>10$. Labels are derived from the Harvard-Oxford cortical and subcortical atlases, and Vogt and Paxinos (2014), specifically for the cingulate cortex. L, Left; R, right; COG, Center of Gravity.

of a single outcome measure is especially not recommended. Here, we nevertheless intended to examine the effects for learners and nonlearners separately, given that the purpose of our article was to better understand conflicting findings with regard to amygdala activation. However, there were only three participants who did not show higher pupil dilation in response to the $\mathrm{CS}^{+}$ compared with the $\mathrm{CS}^{-}$, averaged across all acquisition trials. Instead, we added differential pupil dilation per individual as a separate predictor in a voxel-wise amygdala analysis (probability threshold, $p>0.01$ ), to test whether stronger indices of anticipatory arousal (pupil dilation, $\mathrm{CS}^{+}>\mathrm{CS}^{-}$all acquisition or extinction trials) were associated with stronger amygdala activation, during fear and extinction learning. This was not the case (parametric map for this control analysis available on OSF; https://osf.io/cq5zr/).

\section{Discussion}

In this study, we tested the hypothesis that fear and extinction learning in humans leads to BOLD activation in the amygdala, provided there is a good signal in this area. Analyzing fear-conditioning data from 98 participants, we found little evidence for activation in response to $\mathrm{CS}^{+}$compared with $\mathrm{CS}^{-}$stimuli in the amygdala, despite robust physiological evidence of fear and extinction learning (differential pupil dilation). In fact, large parts of the amygdala responded more strongly to the $\mathrm{CS}^{-}$compared with the $\mathrm{CS}^{+}$during both fear acquisition and extinction learning, suggesting involvement in safety processing or inhibition of fear. In contrast, many other brain areas, such as the midcingulate cortex, anterior insula, and BNST (part of the extended amygdala; Shackman and Fox, 2016), did show activation in response to learned threat. Crucially, there was negligible signal dropout, and, using the same data, we showed robust amygdala activation in response to face compared with house stimuli, indicating that our fMRI sequence managed to obtain a reliable signal in this area.
Both the absence of effects in the amygdala and the presence of effects in the midcingulate cortex and anterior insula are in line with the literature on human fear and extinction learning (Sehlmeyer et al., 2009; Mechias et al., 2010; Fullana et al., 2016, 2018). Still, some studies do report amygdala activation. With regard to older studies, there seems to be a publication bias, for example, a tendency to report uncorrected and weak effects in the amygdala while ignoring strong effects in other brain areas, or including clusters that have a higher probability of belonging to white matter or neighboring regions such as the putamen, pallidum, and hippocampus. However, this does not explain why recent studies leveraging large samples and state-of-the-art methods report amygdala activation in Pavlovian fear learning (e.g., Sjouwerman et al., 2020). Over the years, numerous explanations for conflicting findings have been proposed (Sehlmeyer et al., 2009; Mechias et al., 2010; Fullana et al., 2016, 2018, 2020; Shackman and Fox, 2021), summarized as (1) insufficiently "fear"-provoking conditioning procedures; (2) heterogeneity of experimental designs and analytical methods; and (3) the functional heterogeneity of the amygdala yielding small effects, combined with small study samples (forming the basis for metaanalyses, which also typically exclude results from ROI approaches), leading to lack of statistical power. Below, we will discuss how each of these points relate to the present study.

First, for ethical reasons, human fear-conditioning procedures can only use USs that are moderately aversive, and relatively controllable. While the present study is comparable to other studies regarding shock intensity, and successful fear conditioning and extinction were evident from both pupil dilation and BOLD responses outside the amygdala, the fear elicited by the CS is likely quite different from the distress experienced by nonhuman animals (LeDoux, 2014; Fullana et al., 2016; Haaker et al., 2019).

Second, design parameters and stimulus material may influence amygdala activation in Pavlovian conditioning in humans 


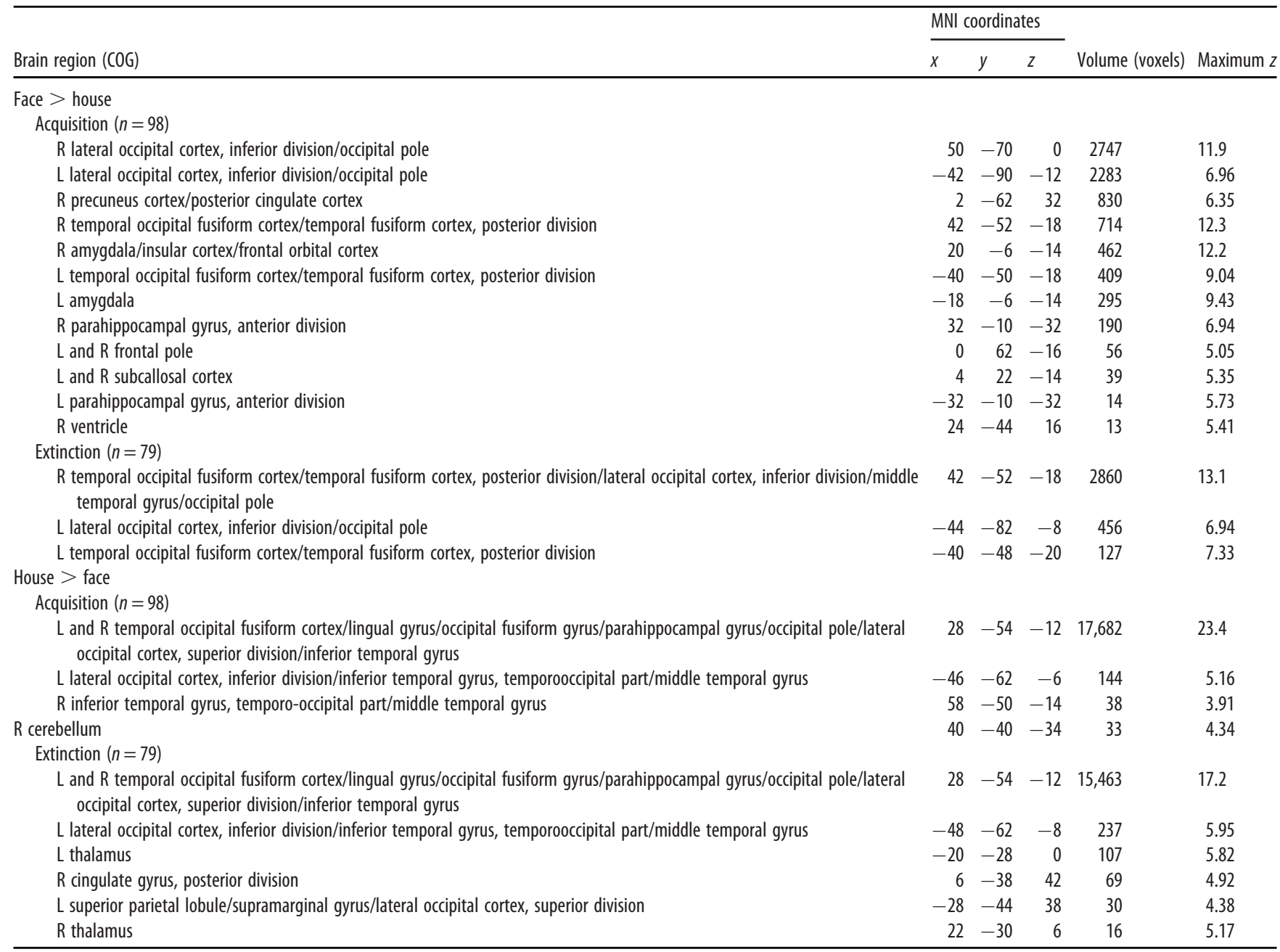

Whole-brain activation (TFCE corrected, $p<0.05$ ) that discriminates the face stimuli from house stimuli. Coordinates are in MNI space and indicate the voxel with the highest $z$ value for each significant cluster. Minimum cluster size reported here: $k>10$. Labels are derived from the Harvard-0xford cortical and subcortical atlases. L, Left; R, right; COG, Center of Gravity.

(and substantially differ from those used in animals; Haaker et al., 2019). Thus far, no pattern has been identified (or systematically investigated) regarding the impact of CS modality (visual, acoustic, olfactory), fear relevance of the CS, threat imminence, uncertainty/certainty of threat (full vs partial reinforcement and, relatedly, US-related confounds), or the inclusion of concurrent measurements (e.g., startle potentiation, online expectancies), though the number of trials and the modality of the US did not appear to have a large impact (Fullana et al., 2016). Furthermore, task-related changes in heart rate may induce spurious activation, given the proximity of the amygdala to large veins (Boubela et al., 2015). Another source of variance stems from task instructions, ranging from participants being told that they might receive shocks during the experiment (Reddan et al., 2018; Sjouwerman et al., 2020), to more explicit instructions about the differential contingencies (the present study; Hermans et al., 2016), to instructed fear learning, where participants are told beforehand which stimulus is followed by a shock and which is not (Phelps et al., 2001; Klumpers et al., 2017; sample 2). Recent large-sample studies on anxiety (without an associative learning component) showed that both certain and uncertain threat anticipation (compared with safety) elicit activation in the dorsal amygdala (Hur et al., 2020, 2021), with certain threats eliciting more activation than uncertain threats. Amygdala deactivation to uncertain threat has also been observed, either in rostral parts only (Hur et al., 2020), or in multiple amygdala nuclei (Morrow et al., 2021). This illustrates the functional heterogeneity of the amygdala, as well as the potential impact of shock predictability, and thus, indirectly, of task instructions. Furthermore, task instructions influence learning rates (i.e., less explicit instructions increase the likelihood that participants remain unaware of the contingencies, and/or fail to show differential physiological responses to threat). In turn, this might affect (the need for) exclusion of subjects (nonlearners) from analyses and, consequently, outcomes (Lonsdorf et al., 2019). Although an early meta-analysis of fear-conditioning studies (Mechias et al., 2010) reported a lack of robust amygdala activation regardless of protocol (instructed or uninstructed fear), a meta-analysis of more recent, large-sample studies is needed to systematically re-evaluate the effect of task instructions. Finally, studies differ in which trials are used to examine threat-related responses, with some averaging across all trials (as we do) and others analyzing early and late phases separately. This is relevant given the mechanistically informed hypothesis and some evidence that the amygdala is only active in the initial stages of fear learning (Büchel et al., 1998; LaBar et al., 1998; Lindner et al., 2015). Although this was not confirmed in a meta-analysis comparing early versus late acquisition (Fullana et al., 2016), results may differ depending on how "early" is defined (Lonsdorf et al., 2019). Alternatively, it may be that the amygdala is not so important for predicting threat as it is for evaluating the outcome of a prediction. 
Analysis of a large sample $(n=173)$ showed that while amygdala activation was not observed during shock anticipation $\left(\mathrm{CS}^{+}>\right.$ $\mathrm{CS}^{-}$), strong responses to shock delivery (i.e., the US) were observed (after rigorous correction for confounds; Klumpers et al., 2017). Although such responses could merely reflect pain, they may also reflect the preference of the amygdala for opportunities for learning, as other research suggests that neuronal plasticity (McNally et al., 2011) and BOLD activation (Michely et al., 2020) in the basolateral amygdala are strongest when the magnitude or occurrence of the US is unexpected.

A third explanation for lack of amygdala activation in human fear learning posits that the relatively low spatial resolution of fMRI (e.g., compared with local field potentials) may be insufficient to study structures like the amygdala, which includes nuclei with dissociable and even opposite function (Swanson and Petrovich, 1998; Reijmers et al., 2007; Quirk and Mueller, 2008; Ciocchi et al., 2010; Haubensak et al., 2010; Orsini and Maren, 2012). In this context, it is important to distinguish Pavlovian conditioning from other types of salience processing. Robust amygdala activation has been observed across a range of different tasks including anticipation or occurrence of unpredictable/predictable aversive stimuli (Hur et al., 2020; Michely et al., 2020; Sambuco et al., 2020), pleasant stimuli such as erotica and reward (Lindquist et al., 2012, 2016), and socially relevant stimuli (Bickart et al., 2014). Detection of responses at the voxel level requires a relatively uniform response from the underlying neuronal code (e.g., $\sim 50 \%$ of amygdala neurons respond to faces; Rutishauser et al., 2015), which is hard to obtain with the sparsely distributed neurons underlying fear memory (Reijmers et al., 2007). Within each voxel, different signals may cancel each other out, and even if they do not, a single activated voxel may disappear with smoothing (which we only did lightly), or with multiple-comparisons correction.

Alternative approaches may offer a solution to some of the challenges mentioned above. For example, while ultra high-resolution BOLD-MRI does not approach the level of neurons, it does seem to offer a somewhat finer-grained mapping of microcircuits involving amygdala subnuclei (Saygin et al., 2017; Torrisi et al., 2018). In addition, analytical approaches such as multivoxel pattern analysis (MVPA) may provide higher sensitivity compared with univariate analyses of BOLD activation in detecting changes related to fear learning and memory, as shown in numerous regions including the amygdala (Bach et al., 2011; Visser et al., 2013, 2015; Braem et al., 2017). MVPA assesses distributed BOLD patterns to characterize the distinctive neural representation of a stimulus or condition. These patterns are used either for (binary) classification analysis or (continuous) representational similarity analysis (RSA; Kriegeskorte et al., 2008). Crucially, patterns are not restricted to voxels that reach a statistical threshold: subthreshold activation and nonresponding voxels can be equally informative, enabling the detection of sparse memory traces (Bach et al., 2011). Relatedly, MVPA does not require, or imply, that voxels preferentially respond to the $\mathrm{CS}^{+}$. In fact, previously observed differential pattern similarity in the amygdala (Visser et al., 2013, 2015) was likely driven by higher responses to the $\mathrm{CS}^{-}$. While dissociable amygdala patterns suggest involvement in fear learning and extinction, the fact that they are driven by stronger responses to learned safety does not fit with how the amygdala is typically portrayed in the literature (but see Genud-Gabai et al., 2013; Morrow et al., 2021).

Aside from being more sensitive, MVPA and RSA can be used to ask a different kind of question: that is, how something is represented in the brain, rather than where exactly the signal originates (Haxby, 2012). This has been leveraged to study the formation, enhancement, persistence, generalization, and extinction of fear memory (Li et al., 2008; Bach et al., 2011; Visser et al., 2011, 2013, 2015, 2016; Hauner et al., 2013; Dunsmoor et al., 2014; de Voogd et al., 2016; Braem et al., 2017; Koizumi et al., 2017; Gerlicher et al., 2018; Reddan et al., 2018; Undeger et al., 2020). Importantly, RSA is relatively independent of methodology (e.g., input can also be electrophysiology; conceptual models), making it a powerful tool for identifying higher-order isomorphisms in representational geometries (e.g., between humans and other primates; Kriegeskorte, 2008) and factors influencing these geometries across species. This opens up avenues for addressing many exciting translational questions on the acquisition and extinction of fear.

\section{Conclusion}

While the amygdala is generally regarded as the integrative center of the brain for fear learning, at present this is not strongly corroborated by neuroimaging evidence in humans. Whether this is because the field needs better methods and more data, because neural processes take place at a different scale than fMRI allows us to image, or because the experience is not comparable across species or paradigms is a topic for future research. Notably, neuroimaging does not allow for causal inferences, and current findings may not generalize to other fear-conditioning protocols; thus, our data primarily highlight the challenges of translational research. Acknowledging that we may currently lack the tools to translate knowledge about the microscopic organization of deep brain structures in nonhuman animals to mesoscale functioning in humans seems preferable over forcefully drawing parallels where this is not justified, or necessary.

\section{References}

Abraham A, Pedregosa F, Eickenberg M, Gervais P, Mueller A, Kossaifi J, Gramfort A, Thirion B, Varoquaux G (2014) Machine learning for neuroimaging with scikit-learn. Front Neuroinform 8:14

Avants BB, Epstein CL, Grossman M, Gee JC (2008) Symmetric diffeomorphic image registration with cross-correlation: evaluating automated labeling of elderly and neurodegenerative brain. Med Image Anal 12:2641.

Bach DR, Weiskopf N, Dolan RJ (2011) A stable sparse fear memory trace in human amygdala. J Neurosci 31:9383-9389.

Bechara A, Tranel D, Damasio H, Adolphs R, Rockland C, Damasio AR (1995) Double dissociation of conditioning and declarative knowledge relative to the amygdala and hippocampus in humans. Science 269:11151118.

Bickart KC, Dickerson BC, Barrett LF (2014) The amygdala as a hub in brain networks that support social life. Neuropsychologia 63:235-248.

Blackford JU, Buckholtz JW, Avery SN, Zald DH (2010) A unique role for the human amygdala in novelty detection. Neuroimage 50:1188-1193.

Blackford JU, Allen AH, Cowan RL, Avery SN (2013) Amygdala and hippocampus fail to habituate to faces in individuals with an inhibited temperament. Soc Cogn Affect Neurosci 8:143-150.

Boubela RN, Kalcher K, Huf W, Seidel EM, Derntl B, Pezawas L, Našel C, Moser E (2015) FMRI measurements of amygdala activation are confounded by stimulus correlated signal fluctuation in nearby veins draining distant brain regions. Sci Rep 5:10499.

Braem S, de Houwer J, Demanet J, Yuen KSL, Kalisch R, Brass M (2017) Pattern analyses reveal separate experience-based fear memories in the human right amygdala. J Neurosci 37:8116-8130.

Büchel C, Morris J, Dolan RJ, Friston KJ (1998) Brain systems mediating aversive conditioning: an event-related fMRI study. Neuron 20:947-957.

Ciocchi S, Herry C, Grenier F, Wolff SBE, Letzkus JJ, Vlachos I, Ehrlich I, Sprengel R, Deisseroth K, Stadler MB, Müller C, Lüthi A (2010) Encoding of conditioned fear in central amygdala inhibitory circuits. Nat 468:277-282. 
Dale AM, Fischl B, Sereno MI (1999) Cortical surface-based analysis. I. Segmentation and surface reconstruction. Neuroimage 9:179-194.

Davis M, Antoniadis EA, Amaral DG, Winslow JT (2008) Acoustic startle reflex in rhesus monkeys: a review. Rev Neurosci 19:171-185.

Davis M, Walker D, Miles L, Grillon C (2010) Phasic vs sustained fear in rats and humans: role of the extended amygdala in fear vs anxiety. Neuropsychopharmacology 35:105-135.

de Voogd LD, Fernández G, Hermans EJ (2016) Awake reactivation of emotional memory traces through hippocampal-neocortical interactions. Neuroimage 134:563-572.

Dunsmoor JE, Kragel PA, Martin A, LaBar KS (2014) Aversive learning modulates cortical representations of object categories. Cereb Cortex 24:2859-2872.

Epstein R, Kanwisher N (1998) A cortical representation the local visual environment. Nature 392:598-601.

Evans AC, Janke AL, Collins DL, Baillet S (2012) Brain templates and atlases. Neuroimage 62:911-922.

Fanselow MS, Pennington ZT (2018) A return to the psychiatric dark ages with a two-system framework for fear. Behav Res Ther 100:24-29.

Finke JB, Roesmann K, Stalder T, Klucken T (2021) Pupil dilation as an index of Pavlovian conditioning. A systematic review and meta-analysis. Neurosci Biobehav Rev 130:351-368.

Fox AS, Shackman AJ (2019) The central extended amygdala in fear and anxiety: closing the gap between mechanistic and neuroimaging research. Neurosci Lett 693:58-67.

Fullana MA, Harrison B, Soriano-Mas C, Vervliet B, Cardoner N, ÀvilaParcet A, Radua J (2016) Neural signatures of human fear conditioning: an updated and extended meta-analysis of fMRI studies. Mol Psychiatry 21:500-508.

Fullana MA, Albajes-Eizagirre A, Soriano-Mas C, Vervliet B, Cardoner N, Benet O, Radua J, Harrison BJ (2018) Fear extinction in the human brain: a meta-analysis of fMRI studies in healthy participants. Neurosci Biobehav Rev 88:16-25.

Fullana MA, Dunsmoor JE, Schruers KRJ, Savage HS, Bach DR, Harrison BJ (2020) Human fear conditioning: from neuroscience to the clinic. Behav Res Ther 124:103528.

Genud-Gabai R, Klavir O, Paz R (2013) Safety signals in the primate amygdala. J Neurosci 33:17986-17994.

Gerlicher A, Tüscher O, Kalisch R (2018) Dopamine-dependent prefrontal reactivations explain long-term benefit of fear extinction. Nat Commun 9:4294.

Gorgolewski KJ, Auer T, Calhoun VD, Craddock RC, Das S, Duff EP, Flandin G, Ghosh SS, Glatard T, Halchenko YO, Handwerker DA, Hanke M, Keator D, Li X, Michael Z, Maumet C, Nichols BN, Nichols TE, Pellman J, Poline J-B, et al. (2016) The brain imaging data structure, a format for organizing and describing outputs of neuroimaging experiments. Sci Data 3:160044.

Greve DN, Fischl B (2009) Accurate and robust brain image alignment using boundary-based registration. Neuroimage 48:63-72.

Haaker J, Maren S, Andreatta M, Merz CJ, Richter J, Richter SH, Meir Drexler S, Lange MD, Jüngling K, Nees F, Seidenbecher T, Fullana MA, Wotjak CT, Lonsdorf TB (2019) Making translation work: harmonizing cross-species methodology in the behavioural neuroscience of Pavlovian fear conditioning. Neurosci Biobehav Rev 107:329-345.

Haubensak W, Kunwar PS, Cai H, Ciocchi S, Wall NR, Ponnusamy R, Biag J, Dong HW, Deisseroth K, Callaway EM, Fanselow MS, Lüthi A, Anderson DJ (2010) Genetic dissection of an amygdala microcircuit that gates conditioned fear. Nature 468:270-276.

Hauner KK, Howard JD, Zelano C, Gottfried JA (2013) Stimulus-specific enhancement of fear extinction during slow-wave sleep. Nat Neurosci 16:1553-1555.

Haxby JV (2012) Multivariate pattern analysis of fMRI: the early beginnings. Neuroimage 62:852-855.

Hermans EJ, Kanen JW, Tambini A, Fernández G, Davachi L, Phelps EA (2016) Persistence of amygdala-hippocampal connectivity and multivoxel correlation structures during awake rest after fear learning predicts long-term expression of fear. Cereb Cortex 27:3028-3041.

Hur J, Smith JF, DeYoung KA, Anderson AS, Kuang J, Kim HC, Tillman RM, Kuhn M, Fox AS, Shackman AJ (2020) Anxiety and the neurobiology of temporally uncertain threat anticipation. J Neurosci 40:7949-7964.

Hur J, Kuhn M, Grogans SE, Anderson AS, Islam S, Kim HC, Tillman RM, Fox AS, Smith JF, DeYoung KA, Shackman AJ (2021) Anxiety-related fronto-cortical activity is associated with dampened stressor reactivity in the real world. Psychol Sci, in press.

Jenkinson M, Bannister P, Brady M, Smith S (2002) Improved optimization for the robust and accurate linear registration and motion correction of brain images. Neuroimage 17:825-841.

Kanwisher N, McDermott J, Chun MM (1997) The fusiform face area: a module in human extrastriate cortex specialized for face perception. J Neurosci 17:4302-4311.

Klein A, Ghosh SS, Bao FS, Giard J, Häme Y, Stavsky E, Lee N, Rossa B, Reuter M, Chaibub Neto E, Keshavan A (2017) Mindboggling morphometry of human brains. PLoS Comput Biol 13:e1005350.

Klumpers F, Morgan B, Terburg D, Stein DJ, van Honk J (2015) Impaired acquisition of classically conditioned fear-potentiated startle reflexes in humans with focal bilateral basolateral amygdala damage. Soc Cogn Affect Neurosci 10:1161-1168.

Klumpers F, Kroes MCW, Baas JMP, Fernández G (2017) How human amygdala and bed nucleus of the stria terminalis may drive distinct defensive responses. J Neurosci 37:9645-9656.

Koizumi A, Amano K, Cortese A, Shibata K, Yoshida W, Seymour B, Kawato M, Lau H (2017) Fear reduction without fear through reinforcement of neural activity that bypasses conscious exposure. Nat Hum Behav 1:

Kriegeskorte N, Mur M, Bandettini P (2008) Representational similarity analysis - connecting the branches of systems neuroscience. Front Syst Neurosci 2:4.

LaBar KS, Gatenby JC, Gore JC, LeDoux JE, Phelps EA (1998) Human amygdala activation during conditioned fear acquisition and extinction: a mixed-trial fMRI study. Neuron 20:937-945.

Lanczos C (1964) Evaluation of noisy data. J Soc Ind Appl Math Ser B Numer Anal 1:76-85.

LeDoux JE (2000) Emotion circuits in the brain. Annu Rev Neurosci 23:155184.

LeDoux JE (2014) Coming to terms with fear. Proc Natl Acad Sci U S A 111:2871-2878.

LeDoux JE (2020) Thoughtful feelings. Curr Biol 30:R619-R623.

Leuchs L, Schneider M, Spoormaker VI (2019) Measuring the conditioned response: a comparison of pupillometry, skin conductance, and startle electromyography. Psychophysiology 56:e13283.

Li W, Howard JD, Parrish TB, Gottfried JA (2008) Aversive learning enhances perceptual and cortical discrimination of indiscriminable odor cues. Science 319:1842-1845.

Lindner K, Neubert J, Pfannmöller J, Lotze M, Hamm AO, Wendt J (2015) Fear-potentiated startle processing in humans: parallel fMRI and orbicularis EMG assessment during cue conditioning and extinction. Int J Psychophysiol 98:535-545.

Lindquist KA, Wager TD, Kober H, Bliss-Moreau E, Barrett L (2012) The brain basis of emotion: a meta-analytic review. Behav Brain Sci 35:121143 .

Lindquist KA, Satpute AB, Wager TD, Weber J, Barrett LF (2016) The brain basis of positive and negative affect: evidence from a meta-analysis of the human neuroimaging literature. Cereb Cortex 26:1910-1922.

Lonsdorf TB, Klingelhöfer-Jens M, Andreatta M, Beckers T, Chalkia A, Gerlicher A, Jentsch VL, Drexler SM, Mertens G, Richter J, Sjouwerman R, Wendt J, Merz CJ (2019) Navigating the garden of forking paths for data exclusions in fear conditioning research. Elife 8:e52465.

McNally GP, Johansen JP, Blair HT (2011) Placing prediction into the fear circuit. Trends Neurosci 34:283-292.

Mechias ML, Etkin A, Kalisch R (2010) A meta-analysis of instructed fear studies: implications for conscious appraisal of threat. Neuroimage 49:1760-1768.

Michely J, Rigoli F, Rutledge RB, Hauser TU, Dolan RJ (2020) Distinct processing of aversive experience in amygdala subregions. Biol Psychiatry Cogn Neurosci Neuroimaging 5:291-300

Morrow K, Dinavahi M, Kim J, Song S, Hu K, Pessoa L (2021) Distributed and multifaceted effects of threat and safety. bioRxiv. Advance online publication. Retrieved November 4, 2021.

Mumford JA, Davis T, Poldrack RA (2014) The impact of study design on pattern estimation for single-trial multivariate pattern analysis. Neuroimage 103:130-138.

Olman CA, Davachi L, Inati S (2009) Distortion and signal loss in medial temporal lobe. PLoS One 4:e8160.

Orsini CA, Maren S (2012) Neural and cellular mechanisms of fear and extinction memory formation. Neurosci Biobehav Rev 36:1773-1802. 
Peterson RA, Reiss S (1992) Anxiety sensitivity index revised test manual. Worthington, OH: International Diagnostic Systems.

Phelps EA, O'Connor KJ, Gatenby JC, Gore JC, Grillon C, Davis M (2001) Activation of the left amygdala to a cognitive representation of fear. Nat Neurosci 4:437-441.

Power JD, Mitra A, Laumann TO, Snyder AZ, Schlaggar BL, Petersen SE (2014) Methods to detect, characterize, and remove motion artifact in resting state fMRI. Neuroimage 84:320-341.

Quirk GJ, Mueller D (2008) Neural mechanisms of extinction learning and retrieval. Neuropsychopharmacology 33:56-72.

Reddan MC, Wager TD, Schiller D (2018) Attenuating neural threat expression with imagination. Neuron 100:994-1005.e4.

Reijmers LG, Perkins BL, Matsuo N, Mayford M (2007) Localization of a stable neural correlate of associative memory. Science 317:1230-1233.

Rutishauser U, Mamelak AN, Adolphs R (2015) The primate amygdala in social perception-insights from electrophysiological recordings and stimulation. Trends Neurosci 38:295-306.

Sambuco N, Costa VD, Lang PJ, Bradley MM (2020) Aversive perception in a threat context: separate and independent neural activation. Biol Psychol 154:107926

Saygin ZM, Kliemann D, Iglesias JE, van der Kouwe AJW, Boyd E, Reuter M, Stevens A, Van Leemput K, McKee A, Frosch MP, Fischl B, Augustinack JC (2017) High-resolution magnetic resonance imaging reveals nuclei of the human amygdala: manual segmentation to automatic atlas. Neuroimage 155:370-382.

Sehlmeyer C, Schöning S, Zwitserlood P, Pfleiderer B, Kircher T, Arolt V, Konrad C (2009) Human fear conditioning and extinction in neuroimaging: a systematic review. PLoS One 4:e5865.

Sevenster D, Visser RM, D'Hooge R (2018) A translational perspective on neural circuits of fear extinction: current promises and challenges. Neurobiol Learn Mem 155:113-126.

Shackman AJ, Fox AS (2016) Contributions of the central extended amygdala to fear and anxiety. J Neurosci 36:8050-8063.

Shackman AJ, Fox AS (2021) Two decades of anxiety neuroimaging research: new insights and a look to the future. Am J Psychiatry 178:106-109.

Siegel JS, Power JD, Dubis JW, Vogel AC, Church JA, Schlaggar BL, Petersen SE (2014) Statistical improvements in functional magnetic resonance imaging analyses produced by censoring high-motion data points. Hum Brain Mapp 35:1981-1996.

Sjouwerman R, Scharfenort R, Lonsdorf TB (2020) Individual differences in fear acquisition: multivariate analyses of different emotional negativity scales, physiological responding, subjective measures, and neural activation. Sci Rep 10:15283.

Spielberger CD, Gorsuch RL, Lushene R, Vagg PR, Jacobs GA (1983) Manual for State-Trait Anxiety Inventory. Palo Alto, CA: Consulting Psychologists Press.

Swanson LW, Petrovich GD (1998) What is the amygdala? Trends Neurosci 21:323-331

Torrisi S, Gorka AX, Gonzalez-Castillo J, O'Connell K, Balderston N, Grillon C, Ernst M (2018) Extended amygdala connectivity changes during sustained shock anticipation. Transl Psychiatry 8:33.

Tovote P, Fadok JP, Lüthi A (2015) Neuronal circuits for fear and anxiety. Nat Rev Neurosci 16:317-331. 2015166.

Undeger I, Visser RM, Olsson A (2020) Neural pattern similarity unveils the integration of social information and aversive learning. Cereb Cortex 30:5410-5419.

van Heukelum S, Mars RB, Guthrie M, Buitelaar JK, Beckmann CF, Tiesinga PHE, Vogt BA, Glennon JC, Havenith MN (2020) Where is cingulate cortex? A cross-species view. Trends Neurosci 43:285-299.

Visser RM, Scholte HS, Kindt M (2011) Associative learning increases trialby-trial similarity of BOLD-MRI patterns. J Neurosci 31:12021-12028.

Visser RM, Scholte HS, Beemsterboer T, Kindt M (2013) Neural pattern similarity predicts long-term fear memory. Nat Neurosci 16:388-390.

Visser RM, Kunze AE, Westhoff B, Scholte HS, Kindt M (2015) Representational similarity analysis offers a preview of the noradrenergic modulation of long-term fear memory at the time of encoding. Psychoneuroendocrinology 55:8-20.

Visser RM, de Haan MIC, Beemsterboer T, Haver P, Kindt M, Scholte HS (2016) Quantifying learning-dependent changes in the brain: single-trial multivoxel pattern analysis requires slow event-related fMRI. Psychophysiology 53:1117-1127.

Vogt BA, Paxinos G (2014) Cytoarchitecture of mouse and rat cingulate cortex with human homologies. Brain Struct Funct 219:185-192.

Weiskopf N, Hutton C, Josephs O, Deichmann R (2006) Optimal EPI parameters for reduction of susceptibility-induced BOLD sensitivity losses: a whole-brain analysis at $3 \mathrm{~T}$ and $1.5 \mathrm{~T}$. Neuroimage 33:493-504.

Winkler AM, Ridgway GR, Webster MA, Smith SM, Nichols TE (2014) Permutation inference for the general linear model. Neuroimage 92:381397.

Zhang Y, Brady M, Smith S (2001) Segmentation of brain MR images through a hidden Markov random field model and the expectation-maximization algorithm. IEEE Trans Med Imaging 20:45-57. 